\title{
Constructing and Testing Alternative Versions of the Fama-French and Carhart Models in the UK
}

\author{
Alan Gregory, Rajesh Tharyan And Angela Christidis*
}

\begin{abstract}
This paper constructs and tests alternative versions of the Fama-French and Carhart models for the UK market with the purpose of providing guidance for researchers interested in asset pricing and event studies. We conduct a comprehensive analysis of such models, forming risk factors using approaches advanced in the recent literature including value-weighted factor components and various decompositions of the risk factors. We also test whether such factor models can at least explain the returns of large firms. We find that versions of the fourfactor model using decomposed and value-weighted factor components are able to explain the cross-section of returns in large firms or in portfolios without extreme momentum exposures. However, we do not find that risk factors are consistently and reliably priced.
\end{abstract}

Keywords: asset pricing, multi factor models, CAPM, Fama-French model, performance evaluation, event studies

\section{INTRODUCTION}

Fama and French (2011) show that regional versions of asset pricing models provide "passable descriptions" of local average returns for portfolios formed on size and value sorts. In general, and specifically for Europe, such models provide better descriptions of returns than global models. Their results provide evidence that asset pricing is not integrated across regions. Whilst Fama and French (2011) are silent on the possible reasons for this, explanations may include differing exposures to macroeconomic factors in smaller or more open economies, differing degrees of internationalisation in companies between countries, and (historically at least) differing accounting treatments affecting the measurement of book values, used to sort stocks on bookto-market ratios. If regional asset pricing models perform better than global models,

\footnotetext{
* The authors are all from the Xfi Centre for Finance and Investment, University of Exeter. The authors would like to thank the Leverhulme Trust for supporting the project which gave rise to this investigation, Peter Pope (editor), and an anonymous referee for their constructive and helpful comments on earlier versions of the paper. The test portfolios and factors underlying this paper can be downloaded from: http://xfi.exeter.ac.uk/researchandpublications/portfoliosandfactors/index.php. (Paper received February 2008, revised version accepted October 2012).
}

Address for correspondence: Professor Alan Gregory, University of Exeter Business School, XFI building, Streatham Campus, University of Exeter, Exeter, EX4 4ST, UK. e-mail: A.Gregory@exeter.ac.uk 
then by extension we might expect country-level models to out-perform regionallevel models. Griffin (2002) notes that country-specific three-factor models explain the average stock returns better than either world models or international versions of the model and suggests that "cost-of-capital calculations, performance measurement and risk analysis using Fama and French-style models are best done on a withincountry basis". Yet to date, there is little evidence to suggest that at a national level the Fama-French (FF) three-factor model adequately describes the cross-section of stock returns in the UK (Fletcher and Kihanda, 2005; Fletcher, 2010; and Michou, Mouselli and Stark, 2012 [hereafter MMS]).

From a practical point of view, firm managers require guidance on project-specific costs of capital for discounting purposes, and also need information on the cost of equity for financing decisions. In the context of UK utility pricing and competition policy, regulators need some model of "fair" rates of return. In addition, researchers interested in event studies, portfolio performance evaluation and market based accounting research are interested in models that adequately describe "normal" returns. Recent examples of such UK investigations that use either a three or four factor model include Gregory and Whittaker (2007), Dedman et al. (2009), Gregory et al. (2010), Dissanaike and Lim (2010), and Agarwal et al. (2011). The absence of evidence that there exists a reliable and robust model for the UK therefore leaves researchers and managers in a difficult position.

Given the above, we extend the search for an improved model that adequately describes the cross-section of returns in the UK in the following ways. We construct and test models using alternative specifications of the factors examined by MMS together with a momentum factor. The momentum factor we construct is the UK equivalent of the UMD factor for the US. ${ }^{1}$ Noting the Cremers, Petajisto and Zitzewitz (2010, hereafter CPZ) critique, we construct the FF factors, by value-weighting (rather than equally weighting) the individual component portfolios. We construct models using decomposed factors, along the lines of Zhang (2008), Fama and French (2011) and CPZ. We examine the APT factors identified in Clare et al. (1997). Finally, we construct and test these alternative models from the sample of the largest 350 firms by market capitalisation, in an attempt to see if we can find a model that works at least for larger and more liquid firms.

We test these alternative factor models against portfolios formed by intersecting sorts on size and book-to-market (BTM), as in Fama and French (2011), and on portfolios formed using sequential sorts on size, BTM and momentum. However, both Lo and MacKinlay (1990) and Lewellen et al. (2010) warn against relying on tests of a model on portfolios whose characteristics have been used to form the factors in the first place. Lewellen et al. (2010, p.182) suggest, inter alia, tests based on portfolios formed on either industries or volatility. MMS follow this advice by testing on industry portfolios, showing that only the $H M L$ factor appears to be priced when tested against this more demanding set of portfolios. In this paper, we follow the Lewellen et al. (2010) suggestion of testing on volatility. We do this partly to extend the range of test portfolios used in the UK, given that MMS test against industry portfolios, and partly 
to avoid difficulties caused by certain industry changes in the $\mathrm{UK}{ }^{2}$ In addition, recent work by Brooks et al. (2011) raise the intriguing possibility that idiosyncratic risk may be priced in the US, which makes testing against portfolios formed on the basis of past volatility interesting.

We conduct tests of our models in two stages. In the first stage we use the F-test of Gibbons, Ross, and Shanken (1989, hereafter GRS). In common with Fama and French (2011), in our first stage tests we find that UK models perform reasonably well when describing returns on test portfolios formed using size and book-to-market, but perform very poorly when tested on portfolios formed on the basis of momentum. This is probably not surprising, given the recent results in MMS and Fletcher (2010). However, we find that two versions of the four-factor model (the Simple 4F model and a CPZ version of the model) do a reasonable job of describing the cross section of returns from test portfolios formed on the basis of volatility.

In the second stage, we go further than Fama and French (2011) in that we run Fama-MacBeth (1973) type tests to examine whether factors are priced. Consistent with the findings of MMS and Fletcher (2010), we find that the factors are not consistently and reliably priced.

One explanation for this poor performance is that there are limits to arbitrage, especially in smaller stocks. These might come about because of liquidity constraints and limits to stock availability in smaller firms, or because short selling constraints might limit the ability of investors to short over-priced "loser" stocks or over-priced "glamour" stocks (Ali and Trombley, 2006; Ali, Huang and Trombley, 2003). Yet as Thomas (2006) points out, it is not difficult to short-sell most large capitalisation stocks. Given that we would expect such limits to arbitrage to be considerably less in larger stocks, we repeat all of our tests on a sub-sample of the 350 largest UK firms, forming both factors and test portfolios from this restricted universe of large stocks. Consistent with this expectation, tests on the large firms sample show that all our models provide reasonable explanations of the cross-section of returns even when portfolios are formed on the basis of momentum. However, the priced factors vary with the test portfolios employed. Based on our findings, our pragmatic advice for fellow researchers using UK data is that, in event study applications either a four factor model, or a decomposed value-weighted four factor model, as proposed by CPZ, might be appropriate, unless the event being studied is likely to feature a large number of smaller stocks. If, however, the objective is to establish a meaningful measure of the expected cost of equity then it is difficult to recommend any one model over the others, given that the factors are not reliably priced.

\section{THE EMPIRICAL MODELS}

We classify the various models that we test into basic models, value-weighted factor components models and decomposed factor models. A detailed description of the construction of the factors used in these models is in a separate section below.

2 In particular, privatisations of utilities and the rail industry during our observation period have led to the emergence of significant new sectors. These changes are essentially the result of political choices and so differ from structural changes brought about by technological innovation. 


\section{(i) Basic Models}

(a) Simple FF

Our first model is the Fama-French (1993) three factor model, which is:

$$
R_{i t}=R_{f t}+\beta_{i}\left(R_{m t}-R_{f t}\right)+s_{i} S M B_{t}+h_{i} H M L_{t}+\varepsilon_{\mathrm{it}}
$$

where $R_{i}$ is the return on an asset $i$, the first term in parentheses is the usual CAPM market risk premium, where $R m$ is the return of a broad market index; $R_{f}$ is the risk free rate of return; and $S M B$ and $H M L$ are respectively size and "value" factors formed from six portfolios formed from two size and three book-to-market (BTM) portfolios.

(b) Simple $4 \mathrm{~F}$

The second model we investigate is a four-factor model similar to the Carhart (1997) model, which in addition to using the three factors of Fama-French (1993) also uses a "winner minus loser" factor to capture the momentum effect. The model is:

$$
R_{i t}=R_{f t}+\beta_{i}\left(R_{m t}-R_{f t}\right)+s_{i} S M B_{t}+h_{i} H M L_{t}+w_{i} U M D_{\mathrm{t}}+\varepsilon_{\mathrm{it}},
$$

where $U M D$ is a momentum factor and the other terms are as in (1) above.

\section{(ii) Value-Weighted Factor Components Models}

CPZ argue that the FF method of equally weighting the six constituent portfolios (from which the $S M B$ and $H M L$ factors are formed) gives a disproportionate weight to small value stocks. So we construct factors using a CPZ-style market capitalisation weighting of the $S M B, H M L$ and $U M D$ component portfolios, which we label $S M B_{-} C P Z$, $H M L_{-} C P Z$ and $U M D_{-} C P Z$.

(a) $C P Z \_F F$

$$
R_{i t}=R_{f t}+\beta_{i}\left(R_{m t}-R_{f t}\right)+s_{i} S M B_{-} C P Z_{t}+h_{i} H M L_{-} C P Z_{t}+\varepsilon_{\mathrm{it}},
$$

(b) $C P Z_{-} 4 F$

$$
R_{i t}=R_{f t}+\beta_{i}\left(R_{m t}-R_{f t}\right)+s_{i} S M B_{-} C P Z_{t}+h_{i} H M L_{-} C P Z_{t}+w_{i} U M D_{-} C P Z_{\mathrm{t}}+\varepsilon_{\mathrm{it}}
$$

(iii) Decomposed Factor Models

Zhang (2008), Fama and French (2011) and CPZ argue that a decomposition of the FF factors may be helpful. The intuition is that value effects may differ between large and small firms. 
(a) FF_4F_decomposed

In our fifth model, we decompose the value factors based on both large and small firms as in Fama-French (2011) and construct our fifth model. This is referred to as the FF decomposition:

$$
R_{i t}=R_{f t}+\beta_{i}\left(R_{m t}-R_{f t}\right)+s_{i} S M B_{t}+h_{i}^{s} H M L_{-} S_{t}+h_{i}^{b} H M L_{-} B_{t}+w_{i} U M D_{\mathrm{t}}+\varepsilon_{i t}
$$

where $H M L_{-} S$ and $H M L_{-} B$ denote the value premium in small firms and large firms respectively.

\section{(b) $\mathrm{CPZ}_{-} 4 \mathrm{~F} \_$decomposed}

In our sixth model, we further decompose the $H M L$ factor into large and small firms ( $B H M L_{-} C P Z$ and $S H M L_{-} C P Z$ ), and also decompose the $S M B$ factor into a mid-cap minus large cap factor $\left(M M B_{-} C P Z\right)$ and a small cap minus mid-cap factor (SMM_CPZ) in the spirit of CPZ. This is referred to as the CPZ decomposition:

$$
\begin{aligned}
R_{i t}= & R_{f t}+\beta_{i}\left(R_{m t}-R_{f t}\right)+s_{i}^{m} M M B_{-} C P Z_{t}+s_{i}^{s} S M M_{-} C P Z_{t}+h_{i}^{b} B H M L_{-} C P Z_{t} \\
& +h_{i}^{s} S H M L_{-} C P Z_{t}+w_{i} U M D_{-} C P Z_{\mathrm{t}}+\varepsilon_{\mathrm{it}} .
\end{aligned}
$$

Note that when testing (6) on the largest 350 firms only, SMM_CPZ as a factor is not calculated.

\section{DATA AND METHOD}

Our data come from various sources and cover the period from October 1980 to December 2010. The monthly stock returns and market capitalisations are from the London Business School Share Price Database (LSPD), The book-values are primarily from Datastream, with missing values filled in with data from: Thomson One Banker; tailored Hemscott data (from the Gregory, Tharyan and Tonks, 2011 study of directors' trading) obtained by subscription; and hand collected data on bankrupt firms from Christidis and Gregory (2010). By combining several data sources we are able to fill in any data gaps in the data available from Datastream.

In the construction of the factors and test portfolios, we only include Main Market stocks and exclude financials, foreign companies and AIM stocks following Nagel (2001) and Dimson, Nagel and Quigley (2003, hereafter DNQ). We also exclude companies with negative or missing book values. The number of UK listed companies in our sample with valid BTM and market capitalisations is 896 in 1980 with the number peaking to 1,323 companies in 1997 . This number then falls away progressively to 1,100 in 2000, ending up with 513 valid companies by the time financials have been excluded in 2010, plus 36 companies with negative BTM ratios. ${ }^{3}$ We now turn to the construction of the portfolios and factors.

3 To cross check this reduction in the number of firms, we compare our data with the market statistics on the London Stock Exchange website, and find that from December 1998 (the earliest month for which data are available on the LSE website) to December 2010, the number of UK listed firms on the Main Market has reduced from 2,087 to 1,004 , a decline of nearly $52 \%$. 


\section{(i) Break Points for Portfolio Construction}

Our central problem in forming the factors and portfolios is to find a UK equivalent for the NYSE break points used to form the portfolios and factors in Ken French's data library. In the particular context of this paper, the London Stock Exchange exhibits a large "tail" of small and illiquid stocks, which are almost certainly not part of the tradable universe of the major institutional investors that make up a large part of the UK market. Use of inappropriate breakpoints will result in factors and test portfolios being heavily weighted by illiquid smaller stocks and lead to incorrect inferences in asset pricing tests, event studies or performance evaluation studies. One way of dealing with this is by altering the break points. The alternative is to employ value weighting in factor construction. CPZ is an example of the latter approach, motivated by concerns about performance evaluation, whereas MMS is an example of the former. As break points and weighting schemes can be viewed as complimentary approaches to the problem of the over-representation of small and illiquid stocks, in this paper we look at the impact of both changing the break points and employing the CPZ style valueweighting scheme.

Fama and French (2011) clearly recognise the importance of using the appropriate break points in forming their regional portfolios, and the issue has received a good deal of attention in the UK research discussed below. GHM and DNQ deal with this by using the median of the largest (by market capitalisation) 350 firms and the $70^{\text {th }}$ percentile of firms, respectively, in forming the size breakpoints for market value, in both cases excluding financial stocks. Gregory et al. (2001) base their BTM breakpoints on the $30^{\text {th }}$ and $70^{\text {th }}$ percentiles of the largest 350 firms, whereas DNQ use the $40^{\text {th }}$ and $60^{\text {th }}$ percentiles. However, more typically, other UK studies (Al-Horani et al., 2003; Fletcher, 2001; Fletcher and Forbes, 2002; Hussain et al., 2002; Liu et al., 1999; and Miles and Timmerman, 1996) use the median of all firms. For the reasons outlined in the introduction, we believe it is important to consider the likely investable universe for large investors, and in this paper we use the largest 350 firms as in Gregory et al. (2001, 2003) and Gregory and Michou (2009, hereafter GM). ${ }^{4}$

\section{(ii) Factor Construction}

In the models (1)-(6) above, $R m-R f$ is the market factor (market risk premium). $R m$ is the total return on the FT All Share Index, and $R f$ (risk free rate) is the monthly return on three month Treasury Bills.

\section{(a) Factors for the Basic Models}

In addition to a market factor, the Simple FF model (1) above uses a $S M B$ (size) and a $H M L$ (value) factor which are constructed from six portfolios formed on size (market capitalisation) and BTM. Our portfolios are formed at the beginning of October in year $t$. Following Agarwal and Taffler (2008), who note that 22\% of UK firms have

4 We also construct and test our models using the alternative Dimson et al. (2003) $70^{\text {th }}$ percentile breakpoints, the Al-Horani et al. $50^{\text {th }}$ percentile breakpoints together with the Fletcher (2001) and Fletcher and Kihanda (2005) factor construction methods. An excellent and detailed review of the methods used in UK portfolio construction can be found in MMS. Given that our evidence on these alternative factor specifications is similar to that in MMS, we do not report these tests in the paper, although full test results are available from the authors on request. 
March year ends, with $37 \%$ of firms having December year ends, we match March year $t$ book value with end of September year $t$ market capitalisation to get the appropriate size and BTM to form the portfolios.

In detail, to form the portfolios, we independently sort our sample firms on market capitalisation and BTM. Sorting on market capitalisation first, we form two size groups "S"-small and "B"-big using the median market capitalisation of the largest 350 companies (our proxy for the Fama-French NYSE break point) in year $t$ as the size break point. Then, sorting on the BTM, we form the three BTM groups, "H"-High, "M"-medium and "L"-Low, using the $30^{\text {th }}$ and $70^{\text {th }}$ percentiles of BTM of the largest 350 firms as break points for the BTM. Using these size and BTM portfolios, we form the following six intersecting portfolios $\mathrm{SH}, \mathrm{SM}, \mathrm{SL}, \mathrm{BH}, \mathrm{BM}$, and $\mathrm{BL}$ where "SH" is the small size, high BTM portfolio, "SL" is the small size, low BTM portfolio, "BL" is the big size, low BTM portfolio, and so on.

These portfolios are then used to form the $S M B$ and $H M L$ factors. The SMB factor is $(\mathrm{SL}+\mathrm{SM}+\mathrm{SH}) / 3-(\mathrm{BL}+\mathrm{BM}+\mathrm{BH}) / 3$ and the HML factor is $(\mathrm{SH}+\mathrm{BH}) / 2-$ $(\mathrm{SL}+\mathrm{BL}) / 2$. Note that in this model, all the components from which $S M B$ and $H M L$ are formed receive equal weighting.

The Simple 4F model, model (2) above, uses an UMD (momentum) factor, which we construct using the methodology described on Ken French's website as follows. Using size and prior (2-12) returns ${ }^{5}$ we first create six portfolios, namely SU, SM, SD, $\mathrm{BU}, \mathrm{BM}$ and $\mathrm{BD}$ where $\mathrm{SU}$ is a small size and high momentum portfolio, $\mathrm{SM}$ is the small size and medium momentum portfolio, SD is the small size and low momentum portfolio, $\mathrm{BU}$ is the big size and high momentum portfolio and so on. These portfolios, which are formed monthly, are therefore intersections of two portfolios formed on size and three portfolios formed on prior (2-12) return. The monthly size breakpoint (our proxy for the Fama-French NYSE break point) is the market capitalisation of the median firm in the largest 350 companies. The monthly prior (2-12) return breakpoints are the $30^{\text {th }}$ and $70^{\text {th }}$ of prior (2-12) performance of the largest 350 companies each month. The $U M D$ factor is then calculated as $0.5(\mathrm{SU}+\mathrm{BU})-0.5$ $(\mathrm{SD}+\mathrm{BD})$, where $\mathrm{U}$ denotes the high momentum portfolio and $\mathrm{D}$ the low momentum portfolio. As in the case of the $S M B$ and $H M L$ factors, the components used to form the $U M D$ factor are equally weighted.

\section{(b) Factors for the Value-Weighted Components and Decomposed Factor Models}

The $S M B_{-} C P Z, H M L_{-} C P Z$ and $U M D_{-} C P Z$ factors employed in CPZ_FF and CPZ_4F, model (3) and model (4) above, are calculated by replacing the equal weighting of the components of the $S M B, H M L$ and $U M D$ factors (used in (1) and (2) above) with a value weighting based on the market capitalisation of the SH, SM, SL, BH, BM BL, $\mathrm{SU}, \mathrm{BU}, \mathrm{SD}$ and BD components.

The decomposition of $H M L$ used in $\mathrm{FF}_{-} 4 \mathrm{~F}_{-}$decomposed model (5), uses $H M L_{-} S$ which is constructed as (SH-SL) and $H M L_{-} B$ which is constructed as (BH-BL). In order to separate the $S M B$ factor into mid-cap ( $\left.M M B_{-} C P Z\right)$ and small-cap (SMM_CPZ) elements for the CPZ_4F decomposed model (6), the value-weighted return on the upper quartile firms in the largest 350 firms is used as a proxy for the returns on the 
Figure 1

\section{Construction of SMB, HML, UMD, HML_S and HML_B, SMB_CPZ, UMD_CPZ, BHML_CPZ, SHML_CPZ Risk Factors}
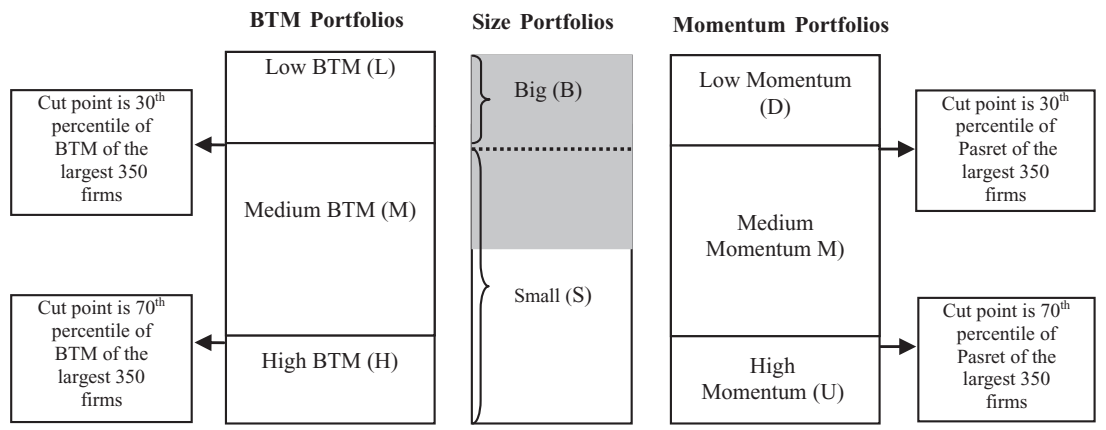

Notes:

The shading represents the largest 350 firms, the dotted line represents the median of the largest 350 firms.

\section{Construction of the factors:}

$\mathrm{SMB}=(\mathrm{SL}+\mathrm{SM}+\mathrm{SH}) / 3-(\mathrm{BL}+\mathrm{BM}+\mathrm{BH}) / 3$

$\mathrm{HML}=(\mathrm{SH}+\mathrm{BH}) / 2-(\mathrm{SL}+\mathrm{BL}) / 2$

$\mathrm{UMD}=0.5(\mathrm{SU}+\mathrm{BU})-0.5(\mathrm{SD}+\mathrm{BD})$

HML_S $=$ SH-SL

HML_B = BH-BL

$\mathrm{SMB}_{-} \mathrm{CPZ}=\left(\left[\mathrm{SL} * \mathrm{~V}_{\mathrm{SL}}\right]+\left[\mathrm{SM} * \mathrm{~V}_{\mathrm{SM}}\right]+\left[\mathrm{SH} * \mathrm{~V}_{\mathrm{SH}}\right]\right) /\left(\mathrm{V}_{\mathrm{SL}}+\mathrm{V}_{\mathrm{SM}}+\mathrm{V}_{\mathrm{SH}}\right)-\left(\left[\mathrm{BL} * \mathrm{~V}_{\mathrm{BL}}\right]+\left[\mathrm{BM} * \mathrm{~V}_{\mathrm{BM}}\right]+\right.$ $\left.\left[\mathrm{BH} * \mathrm{~V}_{\mathrm{BH}}\right]\right) /\left(\mathrm{V}_{\mathrm{BL}}+\mathrm{V}_{\mathrm{BM}}+\mathrm{V}_{\mathrm{BH}}\right)$

$\mathrm{HML}_{-} \mathrm{CPZ}=\left(\left[\mathrm{SH} * \mathrm{~V}_{\mathrm{SH}}\right]+\left[\mathrm{BH} * \mathrm{~V}_{\mathrm{BH}}\right]\right) /\left(\mathrm{V}_{\mathrm{SH}}+\mathrm{V}_{\mathrm{BH}}\right)-\left(\left[\mathrm{SL} * \mathrm{~V}_{\mathrm{SL}}\right]+\left[\mathrm{BL} * \mathrm{~V}_{\mathrm{BL}}\right]\right) /\left(\mathrm{V}_{\mathrm{SL}}+\mathrm{V}_{\mathrm{BL}}\right)$

$\mathrm{UMD} \_\mathrm{CPZ}=\left(\left[\mathrm{SU} * \mathrm{~V}_{\mathrm{SU}}\right]+\left[\mathrm{BU} * \mathrm{~V}_{\mathrm{BU}}\right]\right) /\left(\mathrm{V}_{\mathrm{SU}}+\mathrm{V}_{\mathrm{BU}}\right)-\left(\left[\mathrm{SD} * \mathrm{~V}_{\mathrm{SD}}\right]+\left[\mathrm{BD} * \mathrm{~V}_{\mathrm{BD}}\right]\right) /\left(\mathrm{V}_{\mathrm{SD}}+\mathrm{V}_{\mathrm{BD}}\right)$

$\mathrm{BHML} \_\mathrm{CPZ}=\left[\mathrm{BH} * \mathrm{~V}_{\mathrm{BH}}\right] /\left(\mathrm{V}_{\mathrm{BL}}+\mathrm{V}_{\mathrm{BM}}+\mathrm{V}_{\mathrm{BH}}\right)-\left[\mathrm{BL} * \mathrm{~V}_{\mathrm{BL}}\right] /\left(\mathrm{V}_{\mathrm{BL}}+\mathrm{V}_{\mathrm{BM}}+\mathrm{V}_{\mathrm{BH}}\right)$

$\left.\mathrm{SHML} \_\mathrm{CPZ}=\left[\mathrm{SH} * \mathrm{~V}_{\mathrm{SH}}\right]\right) /\left(\mathrm{V}_{\mathrm{SL}}+\mathrm{V}_{\mathrm{SM}}+\mathrm{V}_{\mathrm{SH}}\right)-\left[\mathrm{SL} * \mathrm{~V}_{\mathrm{SL}}\right] /\left(\mathrm{V}_{\mathrm{SL}}+\mathrm{V}_{\mathrm{SM}}+\mathrm{V}_{\mathrm{SH}}\right)$

Size portfolios are formed annually or monthly (for constructing momentum portfolios only); BTM portfolios formed annually; momentum portfolios formed monthly; Pasret is the prior 2-12 month prior returns; BTM is the book-to-market ratio; and Size is the market capitalisation. Vxx represents the market capitalisation of a particular portfolio (used for value weighting). So, for example, $V_{\mathrm{SL}}$ represents the market capitalisation of a Small Size-Low BTM portfolio, $\mathrm{V}_{\mathrm{MH}}$ represents the market capitalisation of a Mid-Cap-High BTM portfolio etc.

big firms, and the value-weighted return on the remaining 350 firms is used as a proxy for the mid-cap return. Small firm returns are then the value-weighted return on all other firms in the sample.

A diagrammatic representation of the factor construction methods is shown in Figures 1 and 2. Figure 1 shows the construction of $S M B, H M L, U M D, H M L \_S$ and $H M L_{-} B, S M B_{-} C P Z, U M D_{-} C P Z, B H M L_{-} C P Z$ and $S H M L_{-} C P Z$ factors and Figure 2 shows the construction of $M M B_{-} C P Z$ and $S M M_{-} C P Z$ factors.

\section{(iii) Test Portfolio Construction}

As with the portfolios used to form the factors, the test portfolios are formed at the beginning of October of each year $t$. In detail, we construct the following valueweighted portfolios for use in our tests of asset pricing models: ${ }^{6}$

6 We actually employed a wider range of test portfolios but in the interests of brevity we do not detail all of the portfolios we used here. The whole range of test portfolios based on size, book-to-market, momentum and varying combinations of these are available on our website at the following address: http://xfi.exeter.ac.uk/researchandpublications/portfoliosandfactors/index.php 
Figure 2

Construction of MMB_CPZ, and SMM_CPZ Risk Factors

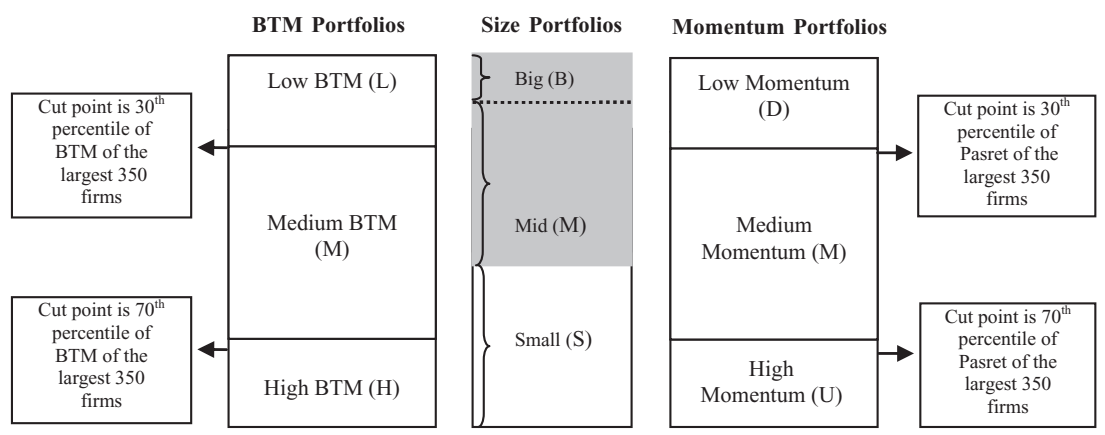

Notes:

Shading represents the largest 350 firms. The dotted line represents the upper quartile of the largest 350 firms.

Construction of the factors:

$\mathrm{MMB}_{-} \mathrm{CPZ}=\left(\left(\mathrm{ML} * \mathrm{~V}_{\mathrm{ML}}+\mathrm{MM} * \mathrm{~V}_{\mathrm{MM}}+\mathrm{MH} * \mathrm{~V}_{\mathrm{MH}}\right)\right] /\left(\mathrm{V}_{\mathrm{ML}}+\mathrm{V}_{\mathrm{MM}}+\mathrm{V}_{\mathrm{MH}}\right)-\left[\left(\mathrm{BL} * \mathrm{~V}_{\mathrm{BL}}+\mathrm{BM} * \mathrm{~V}_{\mathrm{BM}}+\mathrm{BH} *\right.\right.$ $\left.\left.\mathrm{V}_{\mathrm{BH}}\right)\right] /\left(\mathrm{V}_{\mathrm{BH}}+\mathrm{V}_{\mathrm{BM}}+\mathrm{V}_{\mathrm{BL}}\right)$

SMM_CPZ $=\left(\left[\mathrm{SL} * \mathrm{~V}_{\mathrm{SL}}\right]+\left[\mathrm{SM} * \mathrm{~V}_{\mathrm{SM}}\right]+\left[\mathrm{SH} * \mathrm{~V}_{\mathrm{SH}}\right]\right) /\left(\mathrm{V}_{\mathrm{SL}}+\mathrm{V}_{\mathrm{SM}}+\mathrm{V}_{\mathrm{SH}}\right)-\left[\left(\mathrm{MH} * \mathrm{~V}_{\mathrm{MH}}+\mathrm{MM} * \mathrm{~V}_{\mathrm{MM}}+\right.\right.$ $\left.\left.\mathrm{ML} * \mathrm{~V}_{\mathrm{ML}}\right)\right] /\left(\mathrm{V}_{\mathrm{MH}}+\mathrm{V}_{\mathrm{MM}}+\mathrm{V}_{\mathrm{ML}}\right)$

Size portfolios are formed annually or monthly (for constructing momentum portfolios only); BTM portfolios formed annually; momentum portfolios formed monthly; Pasret is the prior 2-12 month prior returns; BTM is the book-to-market ratio; and Size is the market capitalisation.

$\mathrm{V}_{\mathrm{XX}}$ represents the market capitalisation of a particular portfolio (used for value weighting). So, for

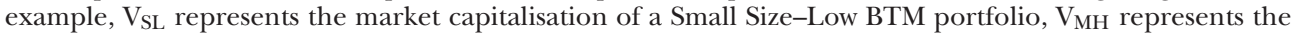
market capitalisation of a Mid-Cap-High BTM portfolio etc.

1. $25(5 \times 5)$ intersecting size and BTM portfolios: We use the whole sample of firms to form these portfolios. The five size portfolios are formed from quartiles of the largest 350 firms plus one portfolio formed from the rest of the sample. For the BTM portfolios we use the BTM quintiles of the largest 350 firms as break points for the BTM to create five BTM groups.

2. $27(3 \times 3 \times 3)$ sequentially sorted size BTM and momentum portfolios: The three size portfolios are formed as two portfolios formed from only the largest 350 firms, using the median market capitalisation of the largest 350 firms as the break point plus one portfolio from the rest of the sample. Then within each size group we create tertiles of BTM to create the three BTM groups. Finally, within each of these nine portfolios we create tertiles of prior 12-month returns to form three momentum groups.

3. 25 portfolios ranked on standard deviation of prior 12-month returns.

4. For our large firm only tests, we form the 25 intersecting size and BTM portfolios using five size and five BTM groups using the largest 350 firms, limit the sequentially sorted size, value and momentum portfolios to a $2 \times 2 \times 3$ sequential sort and finally we limit the volatility portfolios to twelve groups. ${ }^{7}$

We emphasise that our choice of partitioning the size portfolios on the basis of the largest 350 stocks is designed to capture the investable universe for UK institutional

7 We also tested our results using fifteen portfolios, with very similar results. 
investors. Our conversations with practicing fund managers and analysts suggest that large international investors may view the opportunity set of UK firms as comprising the FTSE100 set of firms at best. To take account of these investment criteria we define "large" firms as those with a market capitalisation larger than the median firm of the largest 350 firms by market capitalisation. "Small" becomes any firm that is not in the group of the largest 350 firms. ${ }^{8}$

\section{(iv) Tests of Factor Models}

The central theme of this paper is the asset pricing tests of our models. These testing procedures are described in detail in Cochrane (2001, Ch.12). Essentially, our test is in two stages. In the first stage test, we regress the individual test portfolios on models (1) to (6) and test if the alphas are jointly zero using the Gibbons, Ross and Shanken (1989) or GRS test. More formally, we run time-series regressions as follows:

$$
R_{i t}-R_{f t}=\alpha_{i}+\beta_{i} F_{t}+\varepsilon_{i t}
$$

$R_{i t}$ is the return on a test portfolio $i$ in month $t, R_{f t}$ is the risk-free rate in month $t$, $F_{t}$ is the vector of factors corresponding to the model that is being tested. A regression on each of the test portfolio $i$ yields an intercept $\hat{\alpha}_{i}$. The GRS test is used to then test if these are jointly indistinguishable from zero.

In the second-stage we test whether the factors are reliably priced using the Fama-MacBeth (1973) two-pass regression using either an assumption of constant parameter estimates or rolling 60-monthly estimates of the parameters, which allows for time variation. To adjust for the error-in-variables problem we also compute Shaken (1992) corrected $t$-statistics. More formally, the two-pass Fama-MacBeth test first estimates a vector of estimated factor loadings by regressing the time-series of excess returns on each test portfolio on the vector of risk factors which depend on the particular model being tested. The test then proceeds by running the following cross-sectional regression for each month in the second pass:

$$
R_{i}-R_{f}=\gamma_{0}+\gamma \hat{\beta}_{i}+\varepsilon_{i}
$$

where $R_{i}$ is the return of test portfolio $i, R_{f}$ denotes the risk free return, $\gamma_{0}$ is the constant, $\gamma$ is the vector of cross-sectional regression coefficients and $\hat{\beta}$ is the vector of estimated factor loadings from the first pass regression. From the second pass crosssectional regressions we obtain time series of $\gamma_{0, t}$ and $\gamma_{t}$. The average premium is calculated as the mean of the time series of $\gamma_{t} s$. A cross-sectional $\mathrm{R}^{2}$ tests for goodness of fit and a $\chi^{2}$ test is used to check if the pricing errors are jointly zero. The first pass regressions are run either as rolling regressions or as a single regression over the entire time-series.

8 However, note that we also form 25 "Alternative 350" groups (three portfolios from the largest 350 plus 2 portfolios from the rest and quintiles based on BTM), 25 "DNQ" groups using DNQ cut-points, simple decile and quintile portfolios for both size and BTM, for those who believe that alternative definitions of size and book-to-market are more appropriate. Inferences on factors and test portfolios formed on these groupings do not change. 


\section{RESULTS}

\section{(i) Factor and Portfolio Summary Statistics}

In Table 1, we report the summary statistics for our factors. We note that none of the size factors, nor any of the decomposed elements of the size factors, are significantly different from zero. No matter how they are defined, the $H M L$ factors are significantly different from zero at the $10 \%$ level or less, but breaking down $H M L$ into small and large elements, as in the $\mathrm{FF}_{-} 4 \mathrm{~F}_{-}$decomposed model, raises the standard deviation of the elements so that neither element is reliably different from zero at the $10 \%$ level in two-tailed tests. However, when using the CPZ-decomposition, SHML_CPZ is significantly different from zero, although $B H M L_{-} C P Z$ fails to be. In the Simple FF and Simple $4 \mathrm{~F}$ models, $U M D$ has the highest mean of any of the factors $(0.77 \%$ per month), but also exhibits the greatest negative skewness and the largest kurtosis. Switching to the factors used in the CPZ_FF and CPZ_4F models causes an increase in the mean, median and the standard deviation of the $S M B$ and $H M L$ factors, with a marked decrease in kurtosis for the latter. For $U M D$, the mean and median are reduced, whilst the standard deviation is increased. For the decompositions of the $H M L$ factor, conclusions on whether the effect is larger or smaller in large or small stocks depend upon the method of decomposition.

The correlations in Table 2 reveal that despite the difference in weightings between FF [models (1) and (2)] and CPZ [models (3) and (4)] factors, the correlations are strongly positive: 0.92 in the case of $S M B, 0.88$ in the case of $H M L$ and 0.97 in the case of $U M D$. Decomposing the factors reveals that the large and small firm components of $H M L ; H M L \_S$ and $H M L \_B$ have a significant positive correlation of 0.43 , and $B H M L_{-} C P Z$ and $S H M L_{-} C P Z$ have a correlation of 0.33 . The correlation between the decomposed elements using these alternative factor constructions is strong: 0.98 for the large firm element of $H M L$, and 0.62 for the small firm element. The CPZ decomposition of the size effect reveals that $M M B_{-} C P Z$ and $S M M_{-} C P Z$ have a correlation of only 0.05 . One striking feature of the correlation table is the negative correlation between $H M L$ and momentum. ${ }^{9}$ This is -0.5 in the case of the FF factors, and -0.4 in the case of the CPZ factors. ${ }^{10}$

In Tables 3-5, we report the mean, standard deviation, skewness, maximum, minimum, median and kurtosis of the returns for our value-weighted test portfolios. ${ }^{11}$ Table 3 reports results for 25 intersecting Size and BTM portfolios formed as described above. The tendency within size categories is for returns to increase as BTM ratio increases, although the effect is not completely monotonic in all of the size categories. The general pattern appears to be for skewness to be more negative and kurtosis to be greater in the "glamour" category than the "value" category within any size group, with the exceptions being kurtosis in the second smallest (S2) and medium size groupings.4

9 Clifford (1997) notes a similar effect in the US.

10 This led us to investigate several alternatives in our subsequent tests, which we do not report for space reasons. First, we examined a "pure" Carhart (1997) factor, constructed without intersecting with size effects. Second, we examined whether such a factor performed better in association with factors formed using the Al-Horani et al. (2003), Fletcher (2001), Fletcher and Kihanda (2005), and DNQ (2003) approaches to factor construction. Third, we investigated constructing the factor by interacting momentum and value (instead of size) portfolios. As none of these alternatives changed our reported results in any way, we do not report them here, but results are available from the authors on request.

11 Note that equally weighted versions are also available for download from our website. 


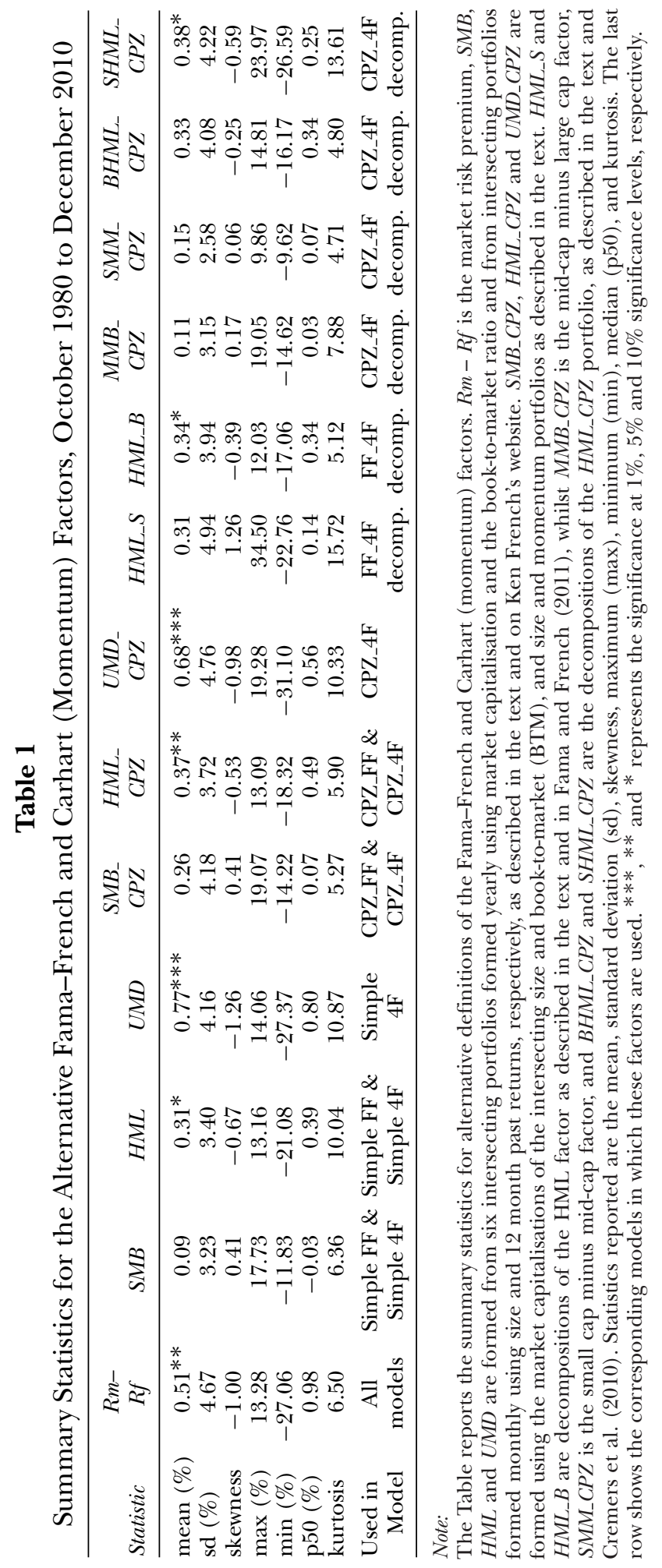




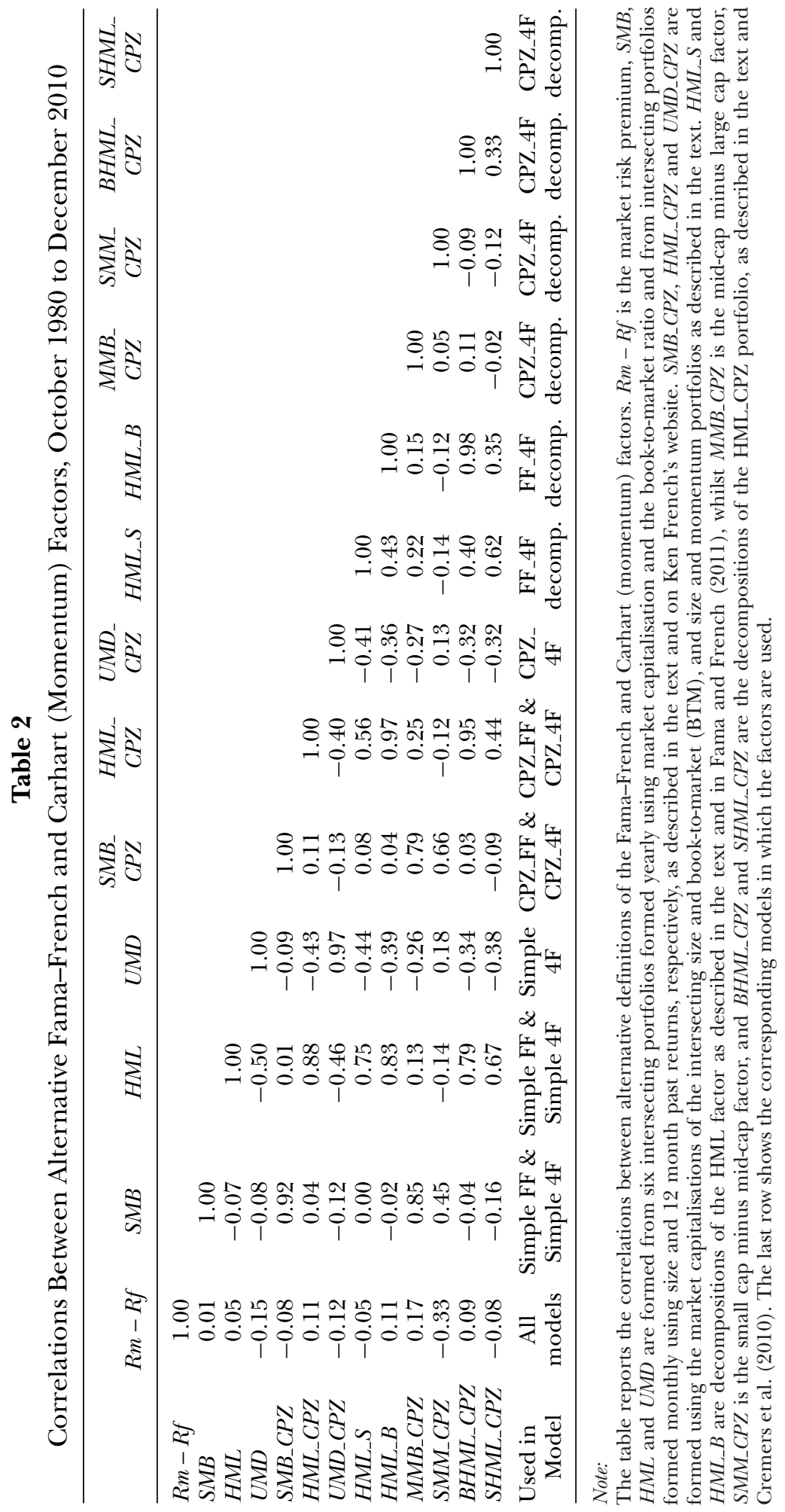




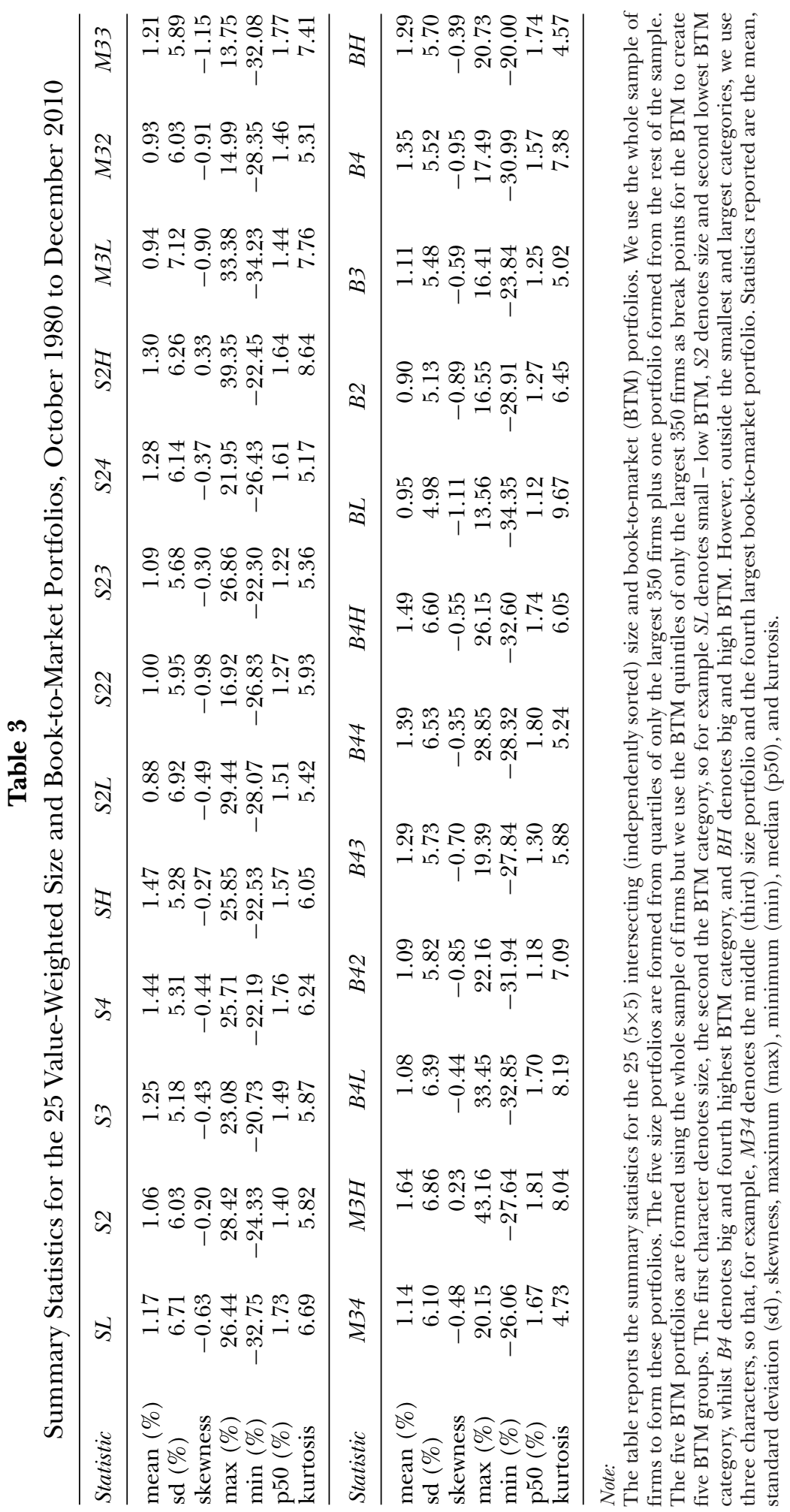




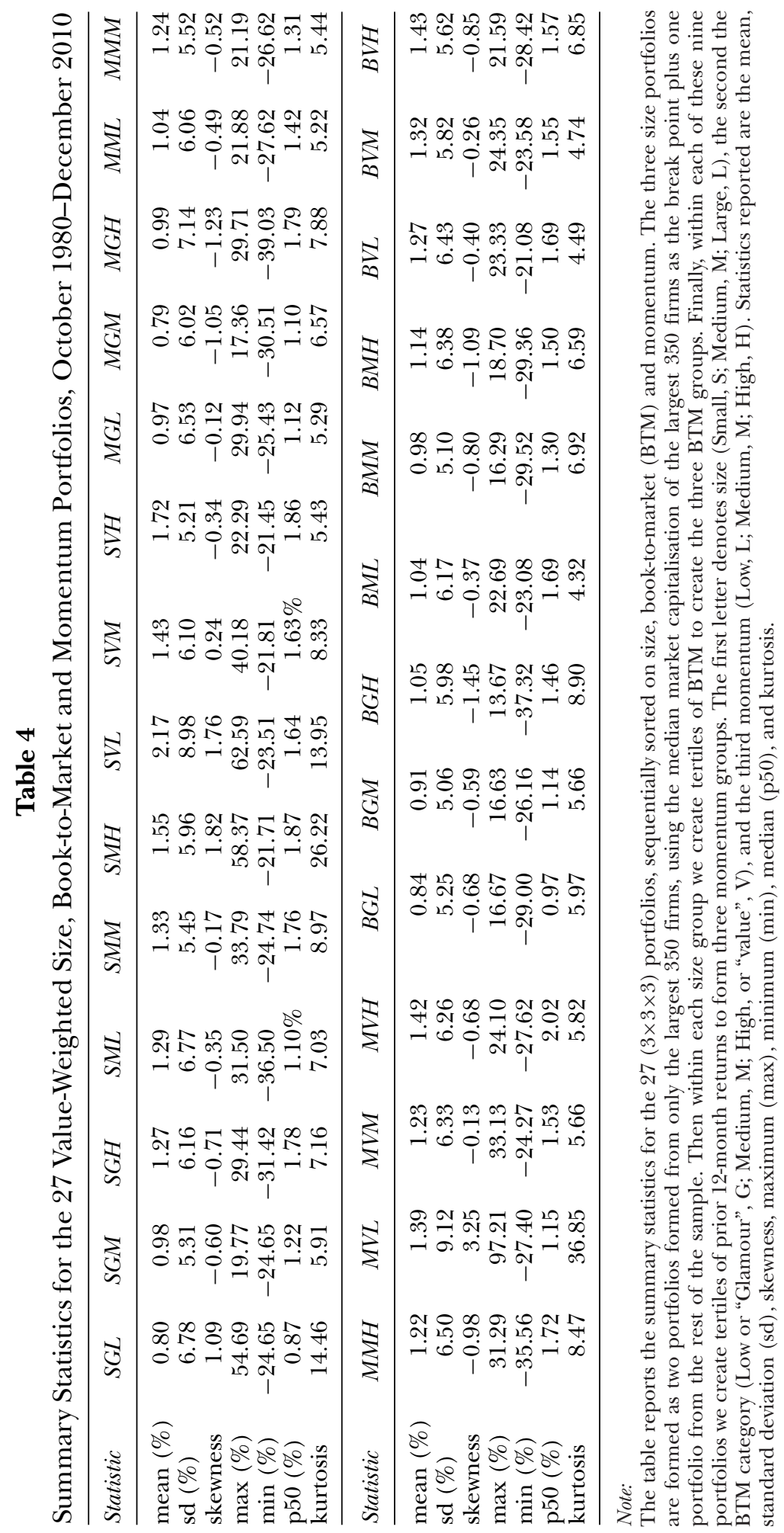




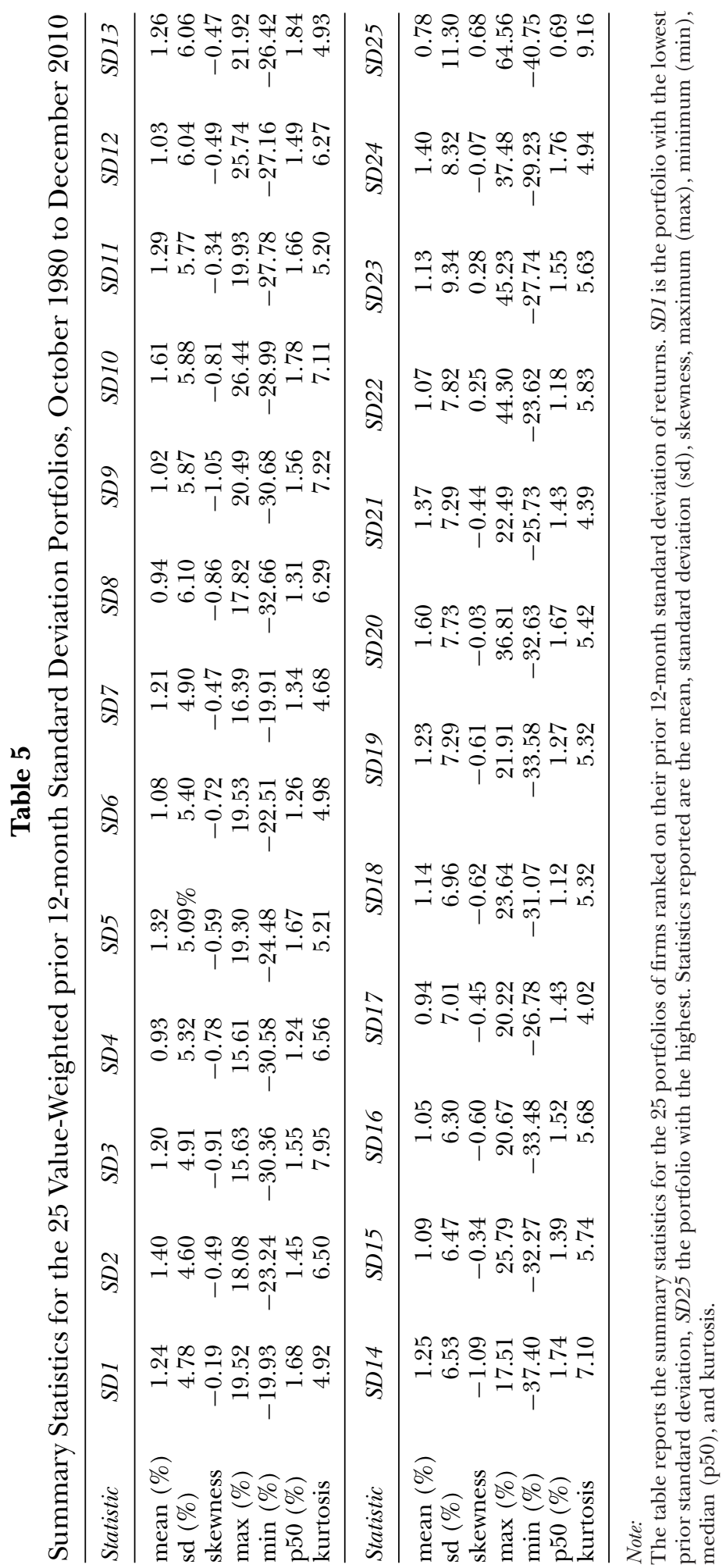


Our next set of portfolios reported in Table 4 are the value-weighted 27 portfolios sequentially sorted on size, BTM and momentum. In the table, the first letter denotes size (Small, S; Medium, M; Large, L), the second letter denotes the BTM category (Low or "Glamour", G; Medium, M; High or "Value", V), and the third momentum (Low, L; Medium, M; High, H). Compared to (unreported) sorts based upon size and momentum, and to the summary factors reported in Table 1, the return patterns here are intriguing as they suggest a much lower momentum effect when BTM is also controlled for. Indeed, within the "small value" set of firms, momentum effects are actually reversed. However, what is striking is that sequentially sorting, as opposed to forming intersecting portfolios, seems to substantially dampen down any momentum effect. Sequential sorting (within any size category ${ }^{12}$ ) has the effect of ensuring each sub-group has equal numbers of firms within it, whereas intersecting portfolios can have quite different numbers of firms within each portfolio. In practice, it emerges that different numbers of firms within sub-categories is only an issue within the smallest market capitalisation quintile, where there is a concentration of firms in the low momentum category. We note that $39 \%$ of all the smallest quintile stocks fall into this "low momentum" group. ${ }^{13}$

Finally, we report the characteristics of the 25 portfolios formed on the basis of prior 12-month standard deviations in Table 5. These portfolios are interesting in several respects. First, past volatility seems to predict future volatility. As we progress from the low standard deviation (SD1) to high standard deviation (SD25) portfolios, standard deviations of the portfolio returns tend to increase. Whilst the effect is not monotonic, the SD25 portfolio has a standard deviation of over twice that of the SD1 portfolio. However, returns do not obviously increase with standard deviation - indeed the lowest mean return portfolio is SD25. Of course, this is not inconsistent with conventional portfolio theory provided that higher risk portfolios have an offsetting effect from lower correlations with other assets. There are no obvious patterns that emerge in either skewness or kurtosis across these portfolios.

\section{(ii) Tests of Factor Models}

\section{(a) Full Sample Results - First Stage Tests}

Tables 6-8 report the results from the first stage tests on the three sets of test portfolios described above. To save space, we do not report the coefficients on the factors for each model. ${ }^{14}$ Each table has six pairs of columns, each pair representing the result from each of our six models. The first column of each pair reports the $\alpha$ (the intercept) and the second column reports its associated $t$-statistic.

In Table 6 , we report the results when our models are tested using the 25 size and BTM portfolios. The Simple FF model passes the GRS test, and only two of the 25 intercept terms are significant at the $5 \%$ level, with both of these failures in the small firm value end categories. Whilst the Simple $4 \mathrm{~F}$ model passes the GRS test, there are now three significant intercepts, two of them in the portfolios that exhibited the same result in the Simple FF model. The additional portfolio that fails the intercept test is

12 Recall that by design we form the size portfolios so that the largest two size groupings by market capitalisation have fewer firms than the smallest size groups.

13 Results for size and momentum portfolios are available on our website as detailed in footnote 6.

14 The individual factor loadings are available from the authors upon request. 


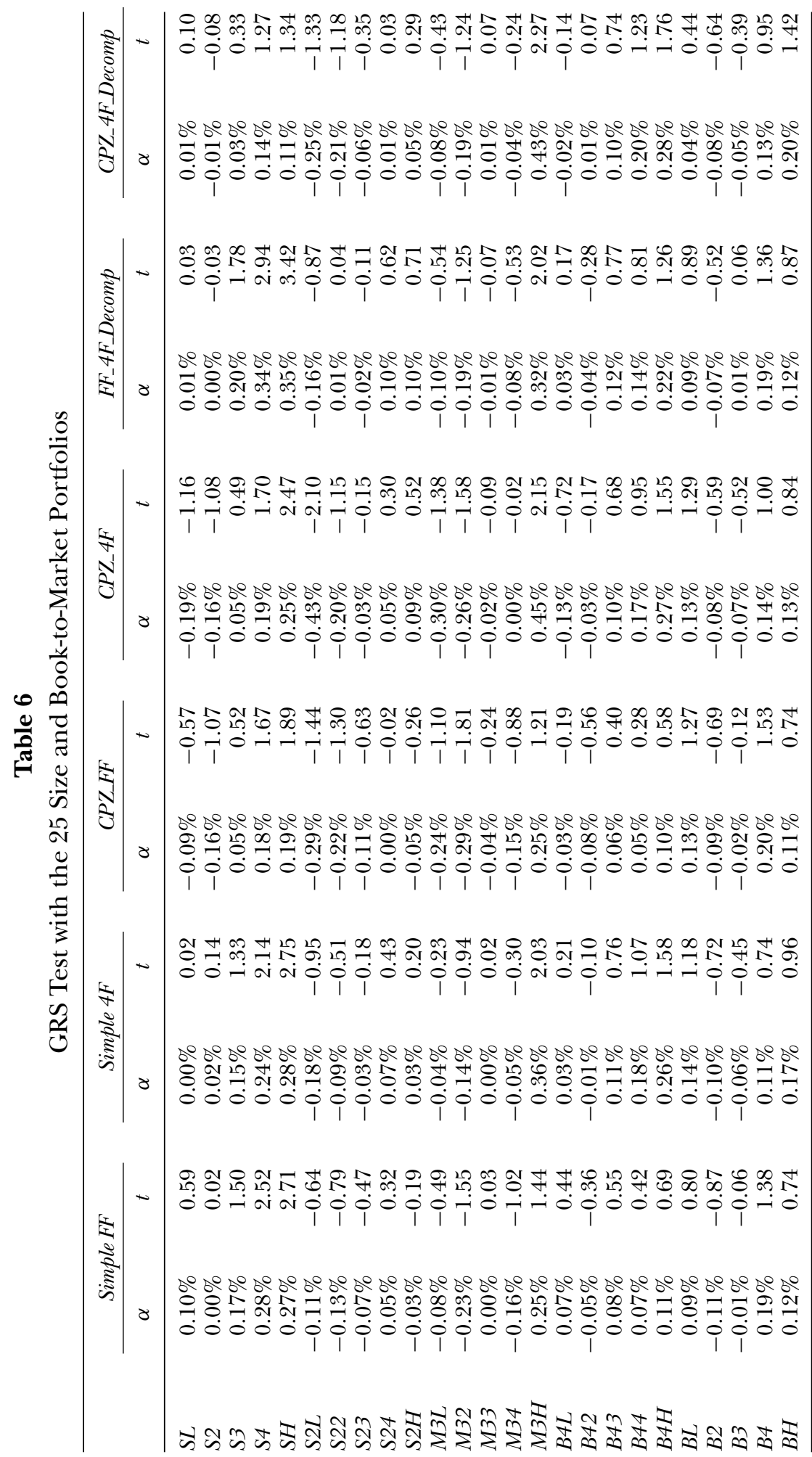




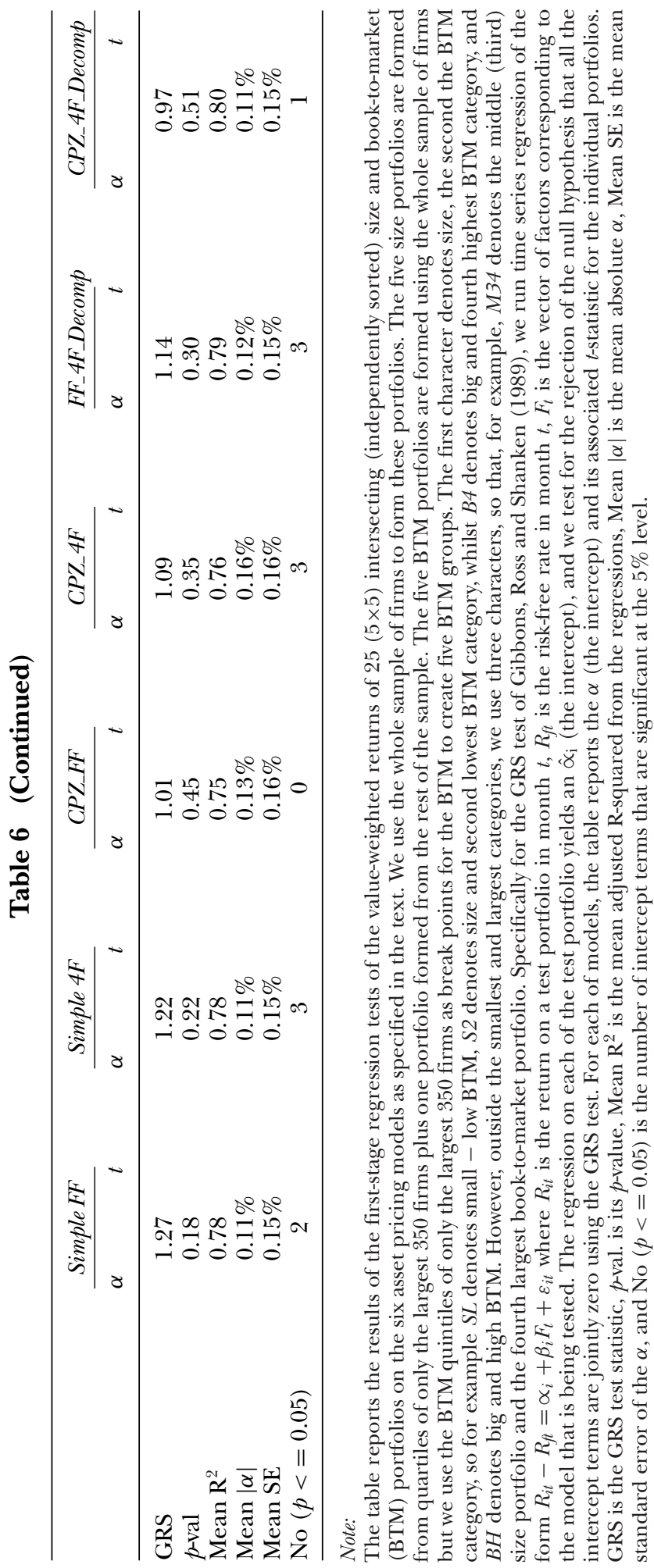




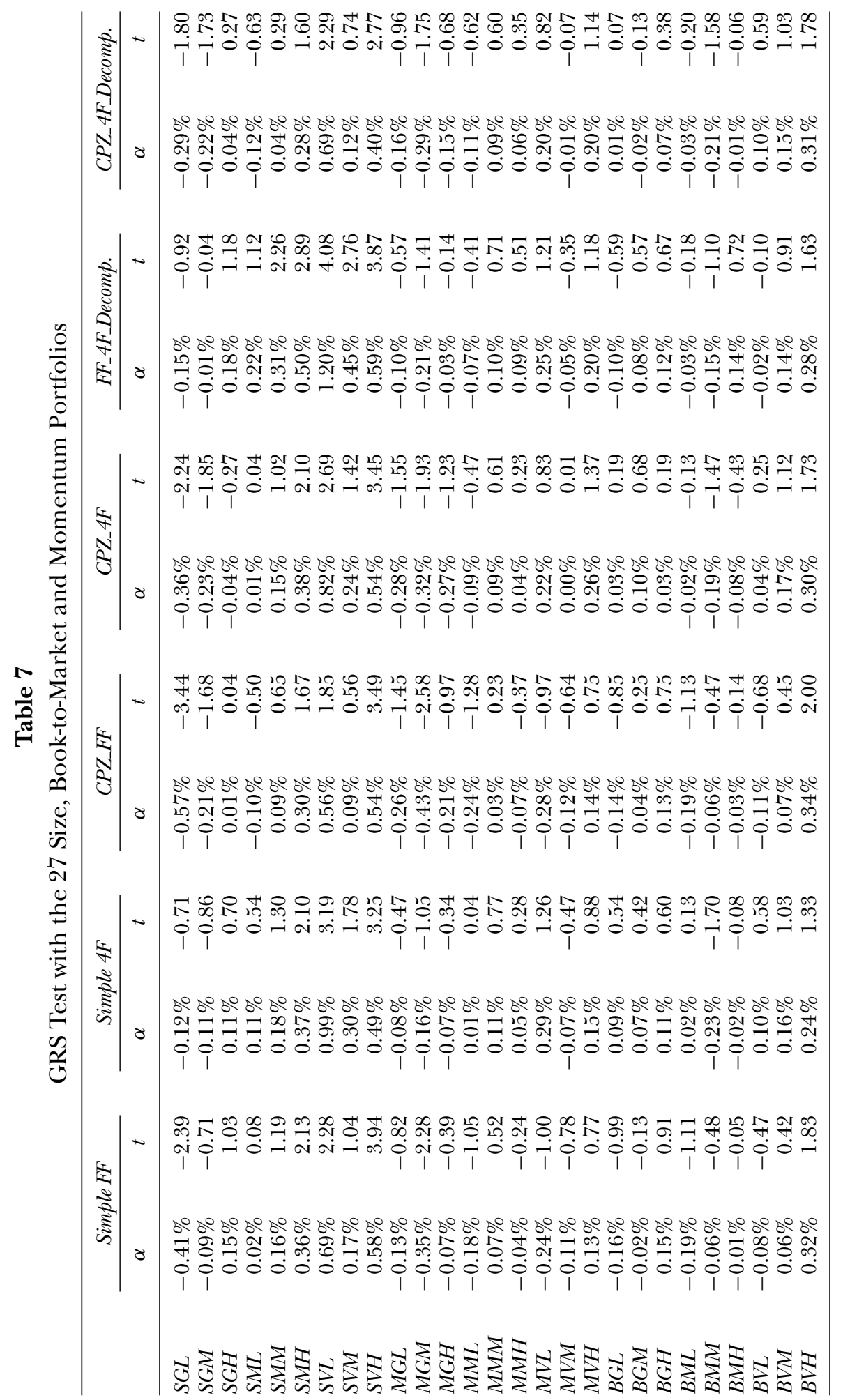




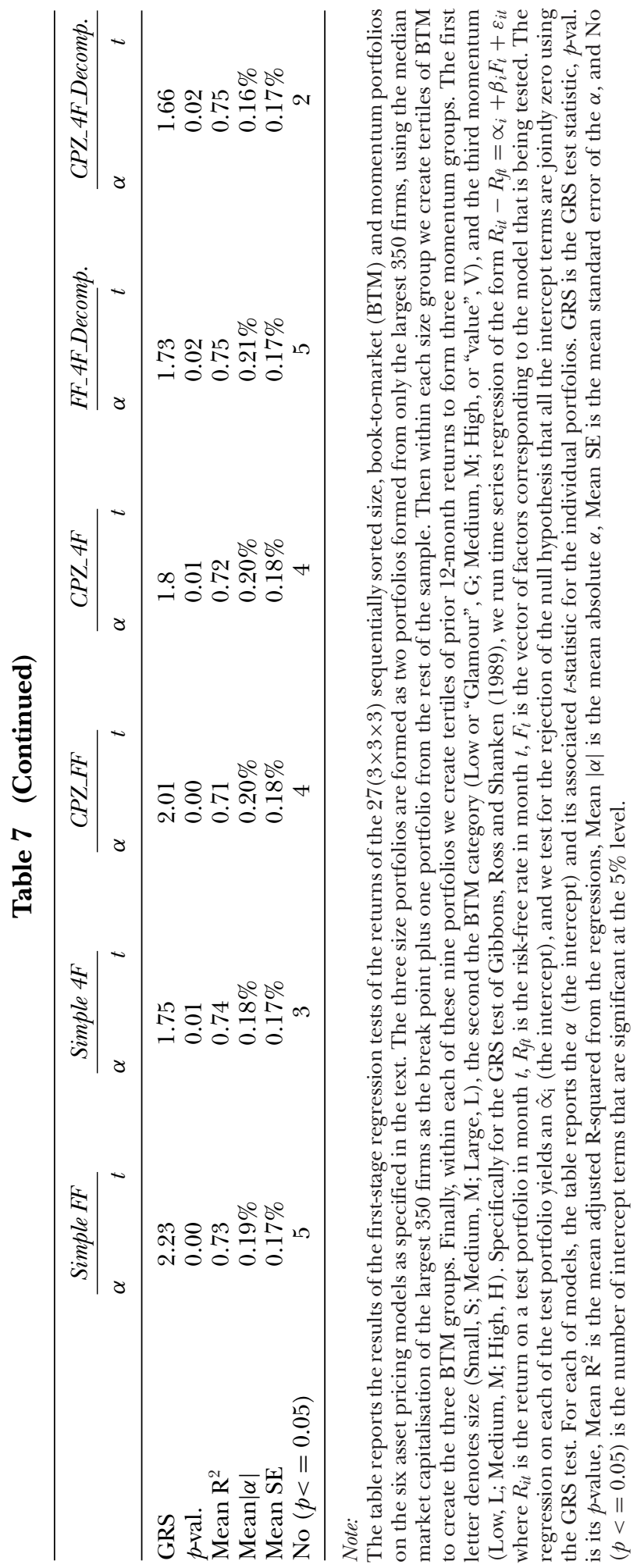




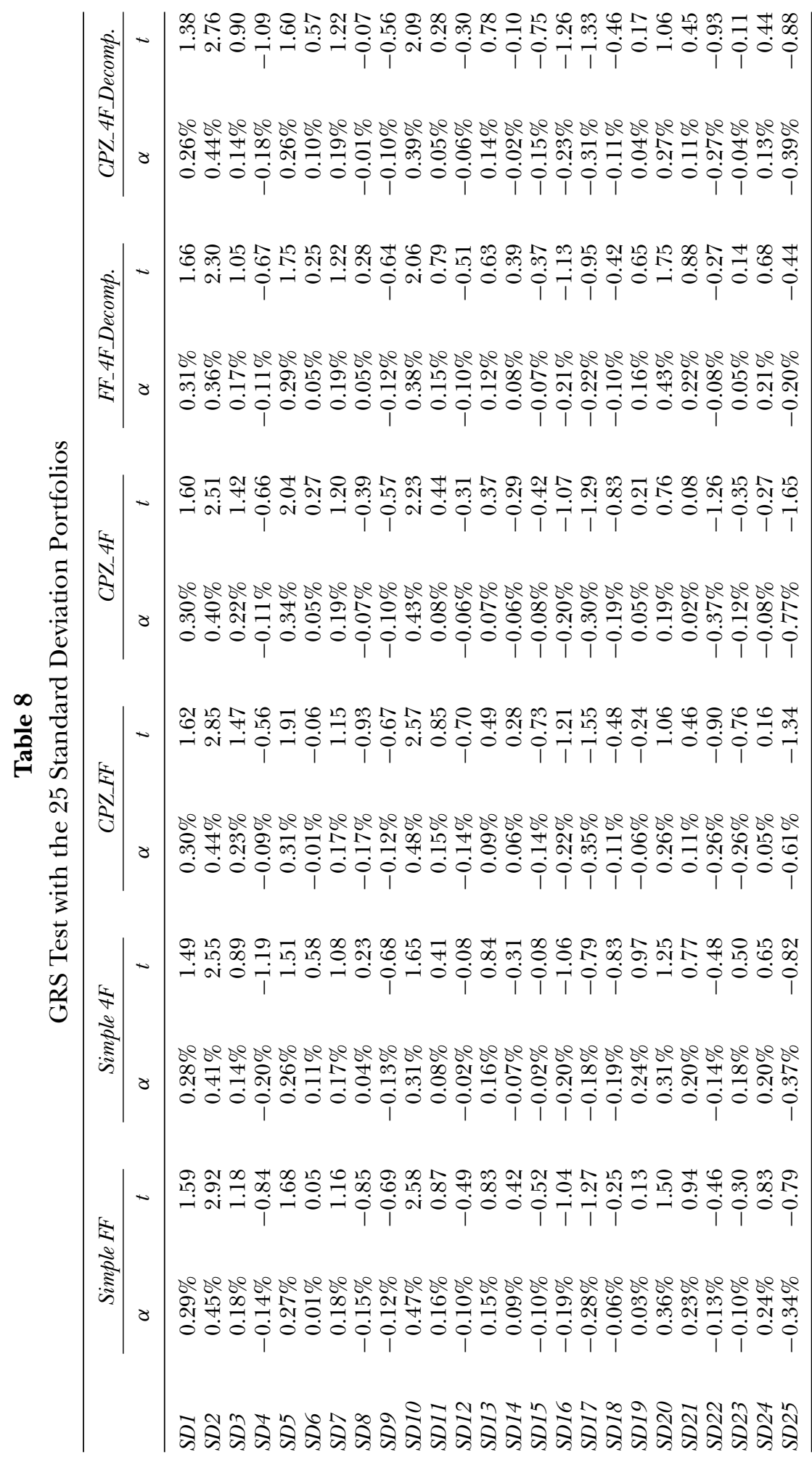




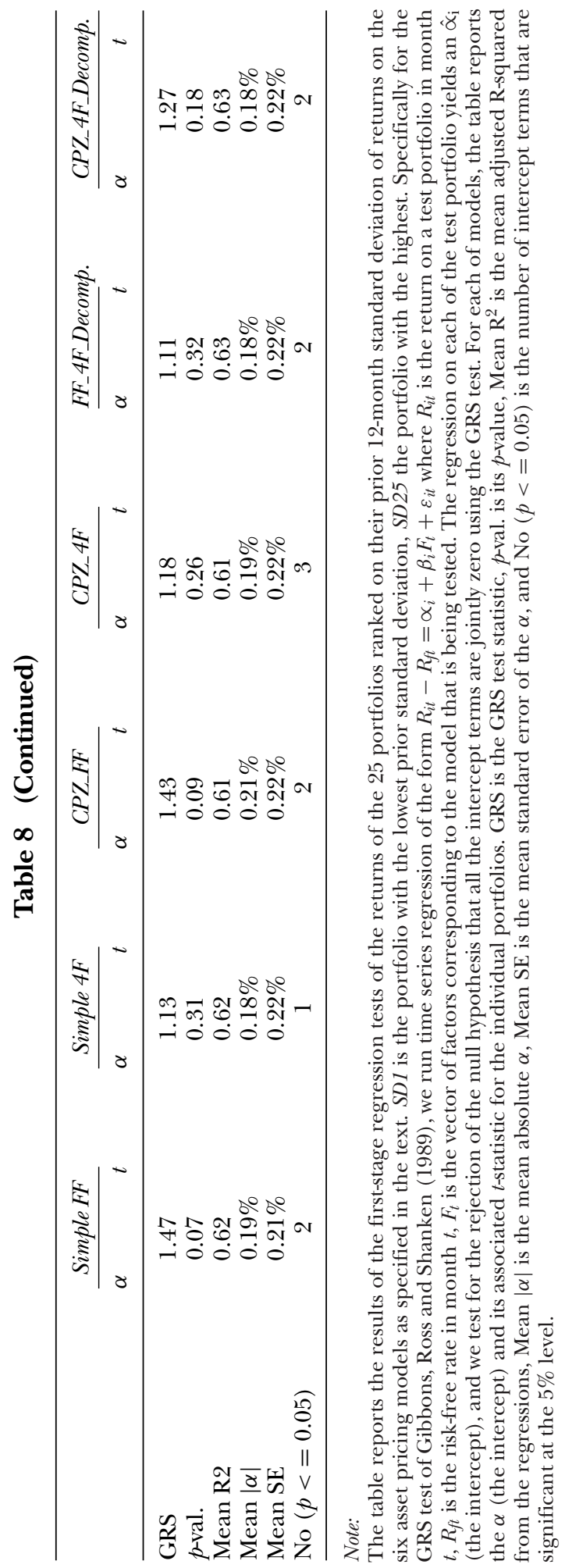


Table 9

Fama-MacBeth Tests with the 25 Size and Book-to-market Portfolios

\begin{tabular}{|c|c|c|c|c|c|c|c|c|}
\hline \multirow{3}{*}{$\begin{array}{l}\text { Panel A } \\
\text { Basic models } \\
\text { Variable }\end{array}$} & \multicolumn{4}{|c|}{ Simple FF } & \multicolumn{4}{|c|}{ Simple $4 F$} \\
\hline & \multicolumn{2}{|c|}{ Single } & \multicolumn{2}{|c|}{ Rolling } & \multicolumn{2}{|c|}{ Single } & \multicolumn{2}{|c|}{ Rolling } \\
\hline & $\gamma$ & $t$-sh & $\gamma$ & $t-s h$ & $\gamma$ & $t$-sh & $\gamma$ & $t$-sh \\
\hline cons & 0.43 & 1.11 & $0.62^{* * *}$ & 1.90 & 0.27 & 0.65 & 0.27 & 0.74 \\
\hline$R m-R f$ & 0.10 & 0.22 & -0.21 & -0.60 & 0.28 & 0.61 & 0.20 & 0.58 \\
\hline$S M B$ & 0.07 & 0.45 & 0.03 & 0.17 & 0.08 & 0.49 & 0.01 & 0.10 \\
\hline$H M L$ & $0.42^{* *}$ & 2.10 & $0.36^{*}$ & 1.78 & $0.50^{* *}$ & 2.53 & $0.47^{* * *}$ & 2.45 \\
\hline$U M D$ & \multirow{2}{*}{\multicolumn{2}{|c|}{0.60}} & \multirow{2}{*}{\multicolumn{2}{|c|}{0.59}} & 0.56 & 0.86 & $0.58^{*}$ & 1.67 \\
\hline Cross-sectional $\mathrm{R}^{2}$ & & & & & \multicolumn{2}{|c|}{0.61} & \multicolumn{2}{|c|}{0.60} \\
\hline$\chi^{2}$ & \multicolumn{2}{|c|}{19.22} & \multicolumn{2}{|c|}{26.72} & 15 & & \multicolumn{2}{|c|}{24.50} \\
\hline$p$-value & \multicolumn{2}{|c|}{0.63} & \multicolumn{2}{|c|}{0.22} & & & \multicolumn{2}{|c|}{0.27} \\
\hline \multirow{2}{*}{$\begin{array}{l}V \text {-W Component } \\
\text { Models }\end{array}$} & \multicolumn{4}{|c|}{$C P Z \_F F$} & \multicolumn{4}{|c|}{$C P Z \_F F$} \\
\hline & \multicolumn{2}{|c|}{ Single } & \multicolumn{2}{|c|}{ Rolling } & \multicolumn{2}{|c|}{ Single } & \multicolumn{2}{|c|}{ Rolling } \\
\hline cons & 0.42 & 1.07 & $0.71^{* *}$ & 2.21 & 0.43 & 1.09 & 0.47 & 1.40 \\
\hline$R m-R f$ & 0.10 & 0.22 & -0.30 & -0.86 & 0.08 & 0.19 & -0.01 & -0.05 \\
\hline$S M B_{-} C P Z$ & 0.16 & 0.72 & 0.11 & 0.48 & 0.16 & 0.71 & 0.09 & 0.39 \\
\hline$H M L \_C P Z$ & $0.57^{* *}$ & 2.30 & $0.46^{* *}$ & 2.09 & $0.55^{* *}$ & 2.54 & $0.59^{* * *}$ & 2.86 \\
\hline$U M D \_C P Z$ & & -0.39 & -0.56 & 0.57 & 1.42 \\
\hline Cross-sectional $\mathrm{R}^{2}$ & 0.6 & & 0 . & & \multicolumn{2}{|c|}{0.61} & 0. & \\
\hline$\chi^{2}$ & 22.2 & & 27. & & 22 & & 27. & \\
\hline$\hat{p}$-value & 0.4 & & 0 & & & & 0. & \\
\hline Panel B & & $F F_{-} 4$ & F_Decomp. & & & $C P Z_{-} 4 \mathrm{I}$ & Decomp. & \\
\hline Decomposed Models & Singt & & Roll & & Sir & & Roll & \\
\hline cons & 0.24 & 0.53 & 0.23 & 0.64 & -0.40 & -0.56 & 0.24 & 0.63 \\
\hline$R m-R f$ & 0.30 & 0.65 & 0.28 & 0.76 & 0.97 & 1.33 & 0.27 & 0.79 \\
\hline$S M B$ & 0.09 & 0.54 & 0.02 & 0.14 & & & & \\
\hline$H M L_{-} S$ & $0.89 * * *$ & 2.58 & 0.45 & 1.53 & & & & \\
\hline$H M L \_B$ & $0.55^{* * *}$ & 2.42 & $0.46^{* *}$ & 2.20 & & & & \\
\hline$U M D$ & 0.79 & 1.20 & $0.55^{*}$ & 1.70 & & & & \\
\hline$M M B_{-} C P Z$ & & & & & 0.08 & 0.45 & 0.12 & 0.63 \\
\hline$S M M_{-} C P Z$ & & & & & 0.15 & 0.92 & 0.03 & 0.20 \\
\hline$B H M L_{-} C P Z$ & & & & & $0.5^{* *}$ & 2.14 & $0.42^{*}$ & 1.89 \\
\hline SHML_CPZ & & & & & $0.59 * *$ & 2.06 & $0.51 *$ & 1.79 \\
\hline$U M D_{-} C P Z$ & & & & & -0.34 & -0.44 & $0.79^{* *}$ & 1.97 \\
\hline Cross-sectional $\mathrm{R}^{2}$ & 0.6 & & 0 . & & & & 0. & \\
\hline$\chi^{2}$ & 12.6 & & 22. & & 18 & & 20. & \\
\hline$p$-value & 0.8 & & 0. & & & & 0. & \\
\hline
\end{tabular}

Note:

The table reports the results of second stage Fama-MacBeth tests of the value-weighted returns of $25(5 \times 5)$ intersecting (independently sorted) size and book-to-market (BTM) portfolios on the six asset pricing models as specified in the text. The two-pass Fama-MacBeth test, proceeds by estimating a vector of estimated factor loadings by regressing the time-series of excess returns on each test portfolio on the vector of risk factors which depends on the particular model being tested. The test then proceeds by running cross-sectional regression for each month in the second pass a $R_{i}-R_{f}=\gamma_{0}+\gamma \hat{\beta}_{i}+\varepsilon_{i} \mathrm{~s}$ Where, $R_{i}$ is the return of test portfolio $i, R_{f}$ denotes the risk free return, $\gamma_{0}$ is the constant, $\gamma^{\prime}$ is the vector of cross-sectional regression coefficients and $\hat{\beta}$ is the vector of estimated factor loadings from the first pass regression. From the second pass cross-sectional regressions we obtain time series of $\gamma_{0 \mathrm{t}}$ and $\gamma_{t}$. The average premium $\gamma$ is calculated as the mean of the time series $\gamma s$. Rm-Rf is the market risk premium, SMB, HML and UMD are 


\section{Table 9 (Continued)}

formed from six intersecting portfolios formed yearly using market capitalisation and the book-to-market ratio and from intersecting portfolios formed monthly using size and 12 month past returns respectively as described in the text and on Ken French's website. SMB_CPZ, HML_CPZ and UMD_CPZ are formed using the market capitalisations of the intersecting size and book-to-market (BTM), and size and momentum portfolios as described in the text. HML_S and HML_B are decompositions of the HML factor as described in the text and in Fama and French (2011), whilst MMB_CPZ is the mid-cap minus large cap factor, SMM_CPZ is the small cap minus mid-cap factor, and BHML_CPZ and SHML_CPZ are the decompositions of the HML_CPZ portfolio, as described in the text and Cremers et al. (2010). The Single column reports the result from first pass regressions run as single regression over the entire time-series while Rolling column reports the results from the 60 month rolling regressions. $\gamma$ is the average coefficient from the FamaMacBeth second pass regressions, t-sh is the Shanken (1992) errors-in-variables corrected t-statistics, The Cross-sectional $\mathrm{R}^{2}$, the $\chi^{2}$ test for the pricing errors are jointly zero and the $\mathrm{p}$-value corresponding to the $\chi^{2}$ are also reported. Panel A reports the results for the Basic models and the Value-weighted factor components models. Panel B reports the results of the Decomposed factor models. ***, ** and ${ }^{*}$ represents the significance at $1 \%, 5 \%$ and $10 \%$ significance levels respectively.

another "value" portfolio, this time M3H. The average adjusted R-squared is almost imperceptibly different between the two models, at 0.783 and 0.784 for the Simple FF and Simple $4 \mathrm{~F}$ models, respectively. Despite the much longer data period and the focus on a single country, these results are broadly in line with the local model results for Europe reported in Tables 3 and 4 of Fama and French (2011).

For the value-weighted factor components models, we observe that both models pass the GRS test and that the mean adjusted R-squared is slightly lower than that of the Simple FF and Simple 4F models. For the CPZ_FF model, we detect no significant alphas at the $5 \%$ level, although three are significant at the $10 \%$ level. Although the improvement is marginal, it does seem that there is some advantage in following the CPZ proposal on value weighting components, at least in terms of the significance of the intercept terms. The CPZ_4F model shows three intercepts being significant at the $5 \%$ level, with one being significant at the $10 \%$ level.

In the last four columns of Table 6 we report the effect of disaggregating the factor components. Doing so seems to increase the mean R-squared compared to the aggregated models, whilst leaving the GRS tests unaffected. The FF decomposition, though, produces four significant alphas, and these are concentrated in the smallest stocks. By contrast, a particularly striking feature of the CPZ decomposition is that it seems able to price the problematic small stock portfolios. The only significant intercept at the $5 \%$ level is $\mathrm{M} 3 \mathrm{H}$, and at the $10 \%$ level $\mathrm{B} 4 \mathrm{H}$, both of which are positive.

Table 7 tests these factors on the sequentially-sorted size, BTM and momentum portfolios. Surprisingly, given these portfolios bear a relationship to the way factors are formed, all six of our models fail the basic GRS test. The Simple FF has five significant alphas at the $5 \%$ level, with four of these occurring in small size groupings. Adding $U M D$ improves matters marginally, with three significant alphas occurring, but the GRS F-test is still a highly significant 1.75.

The central group of columns show that changing the factor component weightings does little to improve the performance of either model. The CPZ 4 F model produces four significant alphas at the $5 \%$ level, all of them amongst smaller firms, whilst the CPZ_FF model produces a similar result overall, but the failures are not concentrated amongst smaller stocks.

The FF decomposition (reported in the final four columns of the table) does nothing to rescue the models, with five significant alphas in the model. However, the CPZ decomposition exhibits only two significant alphas at the $5 \%$ level, although a 
Table 10

Fama-MacBeth Tests with the 27 Size, Book-to-market and Momentum Portfolios

\begin{tabular}{|c|c|c|c|c|c|c|c|c|}
\hline \multirow{3}{*}{$\begin{array}{l}\text { Panel A } \\
\text { Basic Models } \\
\text { Variable }\end{array}$} & \multicolumn{4}{|c|}{ Simple FF } & \multicolumn{4}{|c|}{ Simple $4 F$} \\
\hline & \multicolumn{2}{|l|}{ Single } & \multicolumn{2}{|c|}{ Rolling } & \multicolumn{2}{|c|}{ Single } & \multicolumn{2}{|c|}{ Rolling } \\
\hline & $\gamma$ & $t-s h$ & $\gamma$ & $t-s h$ & $\gamma$ & $t-s h$ & $\gamma$ & $t-s h$ \\
\hline cons & $0.87^{* *}$ & 2.29 & $0.71^{* *}$ & 2.09 & 0.40 & 0.99 & 0.53 & 1.53 \\
\hline$R m-R f$ & -0.36 & -0.85 & -0.34 & -1.03 & 0.13 & 0.31 & -0.09 & -0.28 \\
\hline$S M B$ & 0.05 & 0.28 & 0.08 & 0.43 & 0.11 & 0.62 & 0.08 & 0.42 \\
\hline$H M L$ & $0.48^{* *}$ & 2.33 & 0.35 & 1.62 & $0.62^{* * *}$ & 3.13 & $0.39 *$ & 1.83 \\
\hline$U M D$ & & & & & 0.56 & 1.50 & 0.24 & 0.78 \\
\hline Cross-sectional $\mathrm{R}^{2}$ & 0.57 & & 0.5 & & 0.59 & & & \\
\hline$\chi^{2}$ & 43.35 & & 49.4 & & 37.41 & & & \\
\hline$\hat{p}$-value & 0.00 & & 0.0 & & 0.02 & & & \\
\hline \multirow{2}{*}{$\begin{array}{l}V \text {-W Components } \\
\text { Models }\end{array}$} & \multicolumn{4}{|c|}{$C P Z-F F$} & \multicolumn{4}{|c|}{$C P Z-4 F$} \\
\hline & \multicolumn{2}{|l|}{ Single } & \multicolumn{2}{|c|}{ Rolling } & \multicolumn{2}{|c|}{ Single } & \multicolumn{2}{|c|}{ Rolling } \\
\hline cons & $0.96^{* * *}$ & 2.49 & $0.72^{* *}$ & 2.11 & $0.73^{*}$ & 1.77 & $0.59^{*}$ & 1.67 \\
\hline$R m-R f$ & -0.45 & -1.04 & -0.32 & -0.97 & -0.20 & -0.45 & -0.15 & -0.44 \\
\hline$S M B_{-} C P Z$ & 0.17 & 0.74 & 0.17 & 0.69 & 0.23 & 0.99 & 0.17 & 0.68 \\
\hline$H M L_{-} C P Z$ & $0.58^{* *}$ & 2.29 & 0.33 & 1.33 & $0.81 * * *$ & 3.44 & 0.38 & 1.65 \\
\hline$U M D \_C P Z$ & & & & & 0.39 & 0.89 & 0.23 & 0.63 \\
\hline Cross-sectional $\mathrm{R}^{2}$ & 0.57 & & 0.5 & & 0.58 & & & \\
\hline$\chi^{2}$ & 44.09 & & 44.3 & & 45.10 & & & \\
\hline$p$-value & 0.00 & & 0.0 & & 0.00 & & & \\
\hline
\end{tabular}

\begin{tabular}{|c|c|c|c|c|c|c|c|c|}
\hline \multirow{2}{*}{$\begin{array}{l}\text { Panel B } \\
\text { Decomposed Models }\end{array}$} & \multicolumn{4}{|c|}{ FF_4F_Decomp. } & \multicolumn{4}{|c|}{ CPZ_4F_Decomp. } \\
\hline & \multicolumn{2}{|l|}{ Single } & \multicolumn{2}{|l|}{ Rolling } & \multicolumn{2}{|c|}{ Single } & \multicolumn{2}{|c|}{ Rolling } \\
\hline cons & 0.54 & 1.20 & 0.53 & 1.50 & -0.57 & -0.94 & 0.20 & 0.49 \\
\hline$R m-R f$ & 0.00 & 0.01 & -0.10 & -0.30 & $1.13^{*}$ & 1.92 & 0.28 & 0.72 \\
\hline$S M B$ & 0.10 & 0.59 & 0.07 & 0.36 & & & & \\
\hline$H M L \_S$ & $0.89 * * *$ & 2.53 & $0.46^{*}$ & 1.66 & & & & \\
\hline$H M L \_B$ & $0.72^{* * *}$ & 2.87 & 0.31 & 1.27 & & & & \\
\hline$U M D$ & 0.65 & 1.63 & 0.17 & 0.59 & & & & \\
\hline$M M B_{-} C P Z$ & & & & & -0.02 & -0.12 & 0.00 & 0.03 \\
\hline$S M M_{-} C P Z$ & & & & & 0.25 & 1.37 & 0.25 & 1.40 \\
\hline$B H M L_{-} C P Z$ & & & & & $0.58^{* *}$ & 2.27 & 0.13 & 0.55 \\
\hline$S H M L_{-} C P Z$ & & & & & $1.09 * * *$ & 3.56 & $0.77^{* * *}$ & 2.70 \\
\hline$U M D_{-} C P Z$ & & & & & $0.89^{*}$ & 1.92 & 0.29 & 0.78 \\
\hline Cross-sectional $\mathrm{R}^{2}$ & 0.59 & & 0.58 & & 0.6 & & $0.5 \mathrm{~s}$ & \\
\hline$\chi^{2}$ & 36.42 & & 39.61 & & 30.4 & & 32.03 & \\
\hline$p$-value & 0.02 & & 0.01 & & 0.08 & & 0.05 & \\
\hline
\end{tabular}

Note:

The table reports the results of second stage Fama-MacBeth tests of the value-weighted returns of the $27(3 \times 3 \times 3)$ sequentially sorted size, book-to-market $(\mathrm{BTM})$ and momentum portfolios on the six asset pricing models as specified in the text. The two-pass Fama-MacBeth test, proceeds by estimating a vector of estimated factor loadings by regressing the time-series of excess returns on each test portfolio on the vector of risk factors which depends on the particular model being tested. The test then proceeds by running cross-sectional regression for each month in the second pass as $R_{i}-R_{f}=\gamma_{0}+\gamma \hat{\beta}_{i}+\varepsilon_{i}$ Where, $R_{i}$ is the return of test portfolio $i, R_{f}$ denotes the risk free return, $\gamma_{0}$ is the constant, $\gamma^{\prime}$ is the vector of cross-sectional regression coefficients and $\hat{\beta}$ is the vector of estimated factor loadings from the first pass regression. From the second pass cross-sectional regressions we obtain time series of $\gamma_{0 \mathrm{t}}$ and $\gamma_{t}$. The average premium $\gamma$ is calculated as the mean of the time series $\gamma s$. Rm-Rf is the market risk premium, SMB, HML and UMD are formed from six intersecting portfolios formed yearly using market capitalisation and the book-to-market 


\section{Table 10 (Continued)}

ratio and from intersecting portfolios formed monthly using size and 12 month past returns respectively as described in the text and on Ken French's website. SMB_CPZ, HML_CPZ and UMD_CPZ are formed using the market capitalisations of the intersecting size and book-to-market (BTM), and size and momentum portfolios as described in the text. HML_S and HML_B are decompositions of the HML factor as described in the text and in Fama and French (2011), whilst MMB_CPZ is the mid-cap minus large cap factor, SMM_CPZ is the small cap minus mid-cap factor, and BHML_CPZ and SHML_CPZ are the decompositions of the HML_CPZ portfolio, as described in the text and Cremers et al. (2010). The Single column reports the result from first pass regressions run as single regression over the entire time-series while Rolling column reports the results from the 60 month rolling regressions. $\gamma$ is the average coefficient from the Fama-MacBeth second pass regressions, t-sh is the Shanken (1992) errors-in-variables corrected t-statistics, The Cross-sectional $\mathrm{R}^{2}$, the $\chi^{2}$ test for the pricing errors are jointly zero and the $\mathrm{p}$-value corresponding to the $\chi^{2}$ are also reported. Panel A reports the results for the Basic models and the Value-weighted factor components models. Panel B reports the results of the Decomposed factor models. $* * * * *$ and ${ }^{*}$ represents the significance at $1 \%, 5 \%$ and $10 \%$ significance levels respectively.

further five are significant at the $10 \%$ level. The CPZ decomposition also has the lowest GRS test score and the highest mean adjusted R-squared. Nonetheless, the disappointing ability of any of these models to price portfolios which ultimately reflect, at least to some degree, the characteristics used to form the factors is not promising. These results are in line with those of Fama and French (2011), who also find that their European local models are unable to price portfolios sorted by size and momentum, and conclude that a four factor model is likely to be problematic in applications involving portfolios with momentum tilts.

Table 8 examines the ability of each model to explain the cross-section of returns in portfolios sorted on the basis of prior volatility. In the Simple FF model (Panel A), we see that there are two significant alphas at the $5 \%$ level, but that the model fails the GRS test at the $10 \%$ level. However, the Simple $4 \mathrm{~F}$ model produces only one significant alpha at the $5 \%$ level and passes the GRS test. In the central columns of Table 8 , we see the effect of changing to the CPZ weightings. For the CPZ_FF model, the GRS test fails at the $10 \%$ level, and the number of significant alphas is two. The CPZ_4F model passes this test, though with three significant alphas. As in the Simple FF and Simple $4 \mathrm{~F}$ tests, the less risky portfolios have positive alphas. Here, the most risky (SD25) has a negative alpha, significant at the $10 \%$ level.

In the final four columns of Table 8, we report the results using decomposed factors. Note that we cannot reject the null hypothesis for either model. Both decompositions show the pattern of positive alphas among the less risky portfolios. In conclusion, on the first stage tests, the various specifications of the $4 \mathrm{~F}$ model all pass the GRS test when tested, as suggested by Lewellen et al. (2010), on volatility-ranked portfolios. ${ }^{15}$

\section{(b) Full Sample Results - Second Stage Tests}

We now turn to the second-stage regression tests, and in Tables 9-11 we show the results from the Fama-MacBeth (1973) estimation process using both the assumption of constant parameter estimates (the "Single" regression columns) and rolling

15 This is perhaps surprising, given the results from testing on the sequentially sorted portfolios, and so following Fama and French (2011) we tested our factors on $5 \times 5$ portfolios sorted by intersecting size and momentum. The (unreported) tests show that we can reject the null hypothesis of alphas not being jointly significantly different from zero for all our models. As in that paper, it seems that the real difficulty for our models is pricing momentum effects, particularly in small stocks. 
Table 11

Fama-MacBeth Tests for the Models with the 25 Standard Deviation Portfolios

\begin{tabular}{|c|c|c|c|c|c|c|c|c|}
\hline \multirow{3}{*}{$\begin{array}{l}\text { Panel A } \\
\text { Basic Models } \\
\text { Variable } \\
\end{array}$} & \multicolumn{4}{|c|}{ Simple FF } & \multicolumn{4}{|c|}{ Simple $4 F$} \\
\hline & \multicolumn{2}{|c|}{ Single } & \multicolumn{2}{|c|}{ Rolling } & \multicolumn{2}{|c|}{ Single } & \multicolumn{2}{|c|}{ Rolling } \\
\hline & $\gamma$ & $t$-sh & $\gamma$ & $t$-sh & $\gamma$ & $t-s h$ & $\gamma$ & $t$-sh \\
\hline cons & $0.93^{*}$ & 1.80 & $1.06^{* * *}$ & 2.54 & 0.83 & 1.51 & $1.02 * * *$ & 2.44 \\
\hline$R m-R f$ & -0.36 & -0.63 & -0.67 & -1.64 & -0.25 & -0.45 & -0.64 & -1.57 \\
\hline$S M B$ & 0.16 & 0.57 & 0.26 & 1.13 & 0.16 & 0.54 & 0.34 & 1.46 \\
\hline$H M L$ & 0.28 & 0.64 & 0.38 & 1.47 & 0.25 & 0.55 & $0.44^{*}$ & 1.68 \\
\hline$U M D$ & \multirow{2}{*}{\multicolumn{2}{|c|}{0.48}} & & & 0.56 & 0.91 & -0.35 & -1.07 \\
\hline Cross-sectional $\mathrm{R}^{2}$ & & & \multicolumn{2}{|c|}{0.47} & \multicolumn{2}{|c|}{0.48} & \multicolumn{2}{|c|}{0.48} \\
\hline$x^{2}$ & \multicolumn{2}{|c|}{27.26} & \multicolumn{2}{|c|}{25.27} & \multicolumn{2}{|c|}{20.48} & \multicolumn{2}{|c|}{23.57} \\
\hline$\hat{p}$-value & \multicolumn{2}{|c|}{0.20} & \multicolumn{2}{|c|}{0.28} & 0 . & 49 & \multicolumn{2}{|c|}{0.31} \\
\hline \multirow{2}{*}{$\begin{array}{l}\text { V-W Components } \\
\text { Models. }\end{array}$} & \multicolumn{4}{|c|}{$C P Z-F F$} & \multicolumn{4}{|c|}{$C P Z-4 F$} \\
\hline & \multicolumn{2}{|c|}{ Single } & \multicolumn{2}{|c|}{ Rolling } & \multicolumn{2}{|c|}{ Single } & \multicolumn{2}{|c|}{ Rolling } \\
\hline cons & $0.89^{*}$ & 1.85 & $1.07^{* * *}$ & 2.62 & $0.83^{*}$ & 1.66 & $0.99 * * *$ & 2.45 \\
\hline$R m-R f$ & -0.29 & -0.54 & $-0.67^{*}$ & -1.66 & -0.23 & -0.42 & -0.63 & -1.58 \\
\hline$S M B_{-} C P Z$ & 0.09 & 0.25 & 0.38 & 1.26 & 0.02 & 0.05 & 0.41 & 1.35 \\
\hline$H M L \_C P Z$ & 0.06 & 0.11 & 0.30 & 1.05 & 0.06 & 0.10 & 0.44 & 1.49 \\
\hline$U M D_{-} C P Z$ & & 0.67 & 0.91 & \multirow{2}{*}{\multicolumn{2}{|c|}{$-0.41 \quad{ }^{-1.05}$}} \\
\hline Cross-sectional $\mathrm{R}^{2}$ & \multirow{2}{*}{\multicolumn{2}{|c|}{$\begin{array}{r}0.48 \\
27.88\end{array}$}} & \multicolumn{2}{|c|}{0.47} & \multicolumn{2}{|c|}{0.49} & & \\
\hline$\chi^{2}$ & & & \multirow{2}{*}{\multicolumn{2}{|c|}{$\begin{array}{r}21.91 \\
0.46\end{array}$}} & \multicolumn{2}{|c|}{22.91} & \multicolumn{2}{|c|}{23.10} \\
\hline$p$-value & \multicolumn{2}{|c|}{$\begin{array}{r}27.88 \\
0.18\end{array}$} & & & & 34 & 0.3 & \\
\hline
\end{tabular}

Panel B

Decomposed Factor

FF_4F_Decomp.

CPZ_4F_Decomp.

\begin{tabular}{|c|c|c|c|c|c|c|c|c|}
\hline \multirow{2}{*}{$\begin{array}{l}\text { Models } \\
\text { cons }\end{array}$} & \multicolumn{2}{|c|}{ Single } & \multicolumn{2}{|c|}{ Rolling } & \multicolumn{2}{|c|}{ Single } & \multicolumn{2}{|c|}{ Rolling } \\
\hline & 0.63 & 1.12 & $0.87^{*}$ & 1.91 & 0.81 & 1.45 & $0.81^{*}$ & 1.74 \\
\hline$R m-R f$ & -0.02 & -0.04 & -0.47 & -1.11 & -0.28 & -0.52 & -0.42 & -0.98 \\
\hline$S M B$ & 0.07 & 0.25 & 0.32 & 1.35 & & & & \\
\hline$H M L \_S$ & 0.32 & 0.52 & 0.37 & 0.87 & & & & \\
\hline$H M L \_B$ & -0.62 & -0.91 & 0.46 & 1.47 & & & & \\
\hline$U M D$ & 1.01 & 1.57 & -0.17 & -0.54 & & & & \\
\hline$M M B_{-} C P Z$ & & & & & 0.22 & 0.60 & 0.22 & 0.83 \\
\hline$S M M_{-} C P Z$ & & & & & -0.01 & -0.03 & 0.31 & 1.08 \\
\hline$B H M L_{-} C P Z$ & & & & & -0.46 & -0.66 & $0.58^{*}$ & 1.70 \\
\hline$S H M L_{-} C P Z$ & & & & & 0.26 & 0.57 & 0.28 & 0.78 \\
\hline$U M D_{-} C P Z$ & & & & & $1.37^{*}$ & 1.81 & -0.25 & -0.61 \\
\hline Cross-sectional $\mathrm{R}^{2}$ & \multicolumn{2}{|c|}{0.49} & \multicolumn{2}{|c|}{0.49} & \multicolumn{2}{|c|}{0.49} & \multicolumn{2}{|c|}{0.50} \\
\hline$\chi^{2}$ & \multicolumn{2}{|c|}{16.79} & \multirow{2}{*}{\multicolumn{2}{|c|}{$\begin{array}{r}20.63 \\
0.41\end{array}$}} & \multirow{2}{*}{\multicolumn{2}{|c|}{$\begin{array}{r}15.70 \\
0.67\end{array}$}} & \multicolumn{2}{|c|}{16.56} \\
\hline$p$-value & \multicolumn{2}{|c|}{0.66} & & 0.41 & & & \multicolumn{2}{|c|}{0.61} \\
\hline
\end{tabular}

Note:

The table reports the results of second stage Fama-MacBeth tests of the value-weighted returns of the returns of the 25 portfolios ranked on their prior 12-month standard deviation of returns on the six asset pricing models as specified in the text. The two-pass Fama-MacBeth test, proceeds by estimating a vector of estimated factor loadings by regressing the time-series of excess returns on each test portfolio on the vector of risk factors which depends on the particular model being tested. The test then proceeds by running cross-sectional regressions for each month in the second pass as $R_{i}-R_{f}=\gamma_{0}+\gamma \hat{\beta}_{i}+\varepsilon_{i}$ where, $R_{i}$ is the return of test portfolio $i, R_{f}$ denotes the risk free return, $\gamma_{0}$ is the constant, $\gamma^{\prime}$ is the vector of cross-sectional regression coefficients and $\hat{\beta}$ is the vector of estimated factor loadings from the first pass regression. From the second pass cross-sectional regressions we obtain time series of $\gamma_{0 \mathrm{t}}$ and $\gamma_{t}$. The average premium $\gamma$ is 


\section{Table 11 (Continued)}

calculated as the mean of the time series $\gamma s . R m-R f$ is the market risk premium, $S M B, H M L$ and $U M D$ are formed from six intersecting portfolios formed yearly using market capitalisation and the bookto-market ratio and from intersecting portfolios formed monthly using size and 12 month past returns respectively as described in the text and on Ken French's website. SMB_CPZ, HML_CPZ and $U M D_{-} C P Z$ are formed using the market capitalisations of the intersecting size and book-to-market (BTM), and size and momentum portfolios as described in the text. $H M L_{-} S$ and $H M L_{-} B$ are decompositions of the HML factor as described in the text and in Fama and French (2011), whilst $M M B_{-} C P Z$ is the mid-cap minus large cap factor, $S M M_{-} C P Z$ is the small cap minus mid-cap factor, and BHML_CPZ and $S H M L_{-} C P Z$ are the decompositions of the HML_CPZ portfolio, as described in the text and Cremers et al. (2010). The Single column reports the result from first pass regressions run as single regression over the entire timeseries while Rolling column reports the results from the 60 month rolling regressions. $\gamma$ is the average coefficient from the Fama-MacBeth second pass regressions, t-sh is the Shanken (1992) errors-in-variables corrected t-statistics, The cross-sectional $\mathrm{R}^{2}$, the $\chi^{2}$ test for the pricing errors are jointly zero and the $p$-value corresponding to the $\chi^{2}$ are also reported. Panel A reports the results for the Basic models and the Valueweighted factor components models. Panel B reports the results of the Decomposed factor models. $* * *, * *$ and ${ }^{*}$ represents the significance at $1 \%, 5 \%$ and $10 \%$ significance levels, respectively.

60-monthly estimated coefficients (the "Rolling" regression columns) using our alternative groups of test portfolios. We show results for both three and four factor models, and the estimates are expressed in terms of percent per month. The $t$-statistics (" $t$-sh" in the Tables) are shown after applying the Shanken (1992) corrections for errors-invariables. In each table, Panel A shows the results from the Simple FF and Simple $4 \mathrm{~F}$ models in the top rows, whilst the bottom rows show the results using value weighted components models. Panel B shows results from the decomposed factor models. As we estimate these regressions using excess returns, the intercept should be zero and the coefficients on the factors should represent the market price of the risk factor.

Table 9, Panel A, reports results using the 25 size and BTM portfolios and shows that for the Simple FF model, whether estimated on a fixed or rolling basis, we cannot reject the null hypothesis that pricing errors are significantly different from zero. However, when estimated on a rolling basis the intercept term (_cons) is significantly positive. For both bases, only $H M L$ is priced, and at a level which is not inconsistent with the factor mean in Table 1 . However, $R m-R f$ is not significant. The Simple $4 \mathrm{~F}$ model represents an improvement in terms of both rolling and single regressions satisfying the chi-squared test and the zero-intercept requirement. Note, though, that the implied price of $H M L$ shows a marked increase. The cross-sectional R-squared is also slightly higher. Using CPZ weightings does not change any of the inferences, and except where rolling regressions are used in the context of the CPZ_FF model, the zero intercept requirement is satisfied. The implied factor price on $H M L_{-} C P Z$ is greater than that on $H M L$, and in all cases the price is higher than the mean value reported in Table 1.

The results for the decomposed factor model are reported in Table 9 Panel B. For the FF decomposition, we see that the chi-squared test and zero-intercept requirements are both met. Both $H M L_{-} S$ and $H M L_{-} B$ elements appear to be significantly priced in the single regression model, although the implied price of the former is a good deal higher than implied by the Table 1 mean. Using rolling regressions results in lower estimates and $H M L_{-} S$ being not significantly priced. Again, there is no hint that either market risk or $S M B$ is a priced factor.

For the CPZ decomposition, inferences from the single regression model are similar to those from the FF decomposition. Both $B H M L_{-} C P Z$ and $S H M L_{-} C P Z$ are priced. However, in the rolling regression test whilst these two remain significantly priced, the 
Table 12

GRS Test with Test Portfolios based on the Largest 350 Firms Only

\begin{tabular}{|c|c|c|c|c|c|c|c|c|c|}
\hline \multirow{3}{*}{$\begin{array}{l}\text { Models } \\
\text { Basic Models }\end{array}$} & \multicolumn{9}{|c|}{ Test Portfolios } \\
\hline & \multicolumn{3}{|c|}{$\begin{array}{c}25 \text { Size } \\
\text { and BTM }\end{array}$} & \multicolumn{3}{|c|}{$\begin{array}{l}12 \text { Size, } B / M \\
\text { and Momentum }\end{array}$} & \multicolumn{3}{|c|}{$\begin{array}{l}12 \text { Standard } \\
\text { Deviation }\end{array}$} \\
\hline & $G R S$ & p-val & Mean $R^{2}$ & GRS & p-val & Mean $R^{2}$ & GRS & $p$-val & Mean $R^{2}$ \\
\hline Simple FF & 0.69 & 0.86 & 0.73 & 1.39 & 0.16 & 0.79 & 1.47 & 0.13 & 0.70 \\
\hline Simple $4 \mathrm{~F}$ & 0.87 & 0.64 & 0.73 & 1.25 & 0.24 & 0.79 & 1.05 & 0.40 & 0.70 \\
\hline \multicolumn{10}{|l|}{$V$-W Components model } \\
\hline CPZ-FF & 0.66 & 0.88 & 0.73 & 1.51 & 0.11 & 0.78 & 1.59 & 0.09 & 0.70 \\
\hline CPZ-4F & 0.77 & 0.77 & 0.74 & 1.31 & 0.20 & 0.78 & 1.27 & 0.23 & 0.70 \\
\hline \multicolumn{10}{|l|}{ Decomposed Models } \\
\hline FF_4F_Decomp. & 0.75 & 0.80 & 0.75 & 0.95 & 0.49 & 0.81 & 1.04 & 0.41 & 0.70 \\
\hline CPZ_4F_Decomp. & 0.65 & 0.90 & 0.76 & 1.09 & 0.36 & 0.80 & 1.08 & 0.37 & 0.71 \\
\hline
\end{tabular}

Note:

The table reports the results of the first-stage GRS tests of the returns of the $25(5 \times 5)$ size and book-tomarket $($ BTM) portfolios, $12(2 \times 2 \times 3)$ sequentially sorted size, BTM and momentum portfolios and 12 portfolios ranked on their prior 12-month standard deviation of returns, on the six asset pricing models as described in text, except that both the test portfolios and the risk factors are formed from the largest 350 firms only. Specifically for the GRS test of Gibbons, Ross and Shanken (1989), we run time series regression of the form $R_{i t}-R_{f t}=\propto_{i}+\beta_{i} F_{t}+\varepsilon_{i t}$ where $R_{i t}$ is the return on a test portfolio in month $\mathrm{t}, R_{f t}$ is the risk-free rate in month $t, F t$ is the vector of factors corresponding to the model that is being tested. The regression on each of the test portfolio yields an $\hat{\alpha}_{i}$ (the intercept), and we test for the rejection of the null hypothesis that all the intercept terms are jointly zero using the GRS test. GRS is the GRS F-statistic from the GRS test, $p$-val is the $p$-value for the rejection of the null hypothesis that all the intercept terms are jointly zero and Mean $\mathrm{R}^{2}$ is the mean adjusted $\mathrm{R}$-squared for each model.

$U M D_{-} C P Z$ factor is also significantly priced, and all three factors are priced at a level that is consistent with their sample period means. The consistent result from all of these models is that some form of value premium $(H M L)$ is priced, market risk and size are never priced, and that whether or not momentum is priced is model specific and dependent on rolling, rather than fixed, regressions being estimated.

The results of Fama-MacBeth tests on the sequentially sorted size, BTM and momentum portfolios as reported in Table 10 are disappointing. First, for all our models, no matter whether they are run on a single or rolling estimation basis, we can reject the null hypothesis that the pricing errors are jointly zero. Turning to the individual models, in Panel A for the Simple FF model, the intercept is significantly positive for both single and rolling estimates, although in the case of the former $H M L$ is significantly priced. For the Simple $4 \mathrm{~F}$ model, although the intercept is zero and $H M L$ appears to be priced, the chi-squared test strongly rejects the null of no significant pricing errors. The CPZ weighted factors fail to rescue either model, in that besides the rejection in the chi-squared test all of the intercept terms are also significantly positive, at the $10 \%$ level at least.

The models using decomposed factors in Panel B of Table 10 are a modest improvement, with components being priced in a fashion consistent with pricing in the Table 9 tests, but the chi-squared test is significant (at the $10 \%$ level in the case of the CPZ model). Whilst for all models we can reject the null of pricing errors being jointly zero, the one factor that appears to be priced is some decomposed element of HML. 
Table 13

Fama-MacBeth Tests with the 25 Size and Book-to-Market Portfolios Formed from the Largest 350 Firms

\begin{tabular}{|c|c|c|c|c|c|c|c|c|}
\hline \multirow{3}{*}{$\begin{array}{l}\text { Panel A } \\
\text { Basic Models } \\
\text { Variable } \\
\end{array}$} & \multicolumn{4}{|c|}{ Simple FF } & \multicolumn{4}{|c|}{ Simple $4 F$} \\
\hline & \multicolumn{2}{|c|}{ Single } & \multicolumn{2}{|c|}{ Rolling } & \multicolumn{2}{|c|}{ Single } & \multicolumn{2}{|c|}{ Rolling } \\
\hline & $\gamma$ & $t$-sh & $\gamma$ & $t$-sh & $\gamma$ & $t$-sh & $\gamma$ & $t$-sh \\
\hline cons & -0.23 & -0.44 & 0.14 & 0.41 & -0.24 & -0.45 & 0.06 & 0.17 \\
\hline$R m-R f$ & 0.78 & 1.36 & 0.31 & 0.89 & 0.79 & 1.38 & 0.45 & 1.26 \\
\hline$S M B$ & 0.11 & 0.60 & 0.05 & 0.30 & 0.12 & 0.65 & 0.09 & 0.46 \\
\hline$H M L$ & $0.56^{* *}$ & 2.22 & $0.54^{* *}$ & 2.32 & $0.60^{* *}$ & 2.29 & $0.65^{* * *}$ & 2.75 \\
\hline$U M D$ & \multirow{2}{*}{\multicolumn{2}{|c|}{0.56}} & \multirow{2}{*}{\multicolumn{2}{|c|}{0.55}} & -0.15 & -0.23 & 0.17 & 0.52 \\
\hline Cross-sectional $\mathrm{R}^{2}$ & & & & & \multicolumn{2}{|c|}{0.56} & \multicolumn{2}{|c|}{0.55} \\
\hline$\chi^{2}$ & \multicolumn{2}{|c|}{10.60} & \multicolumn{2}{|c|}{16.70} & \multicolumn{2}{|c|}{10.50} & \multicolumn{2}{|c|}{16.80} \\
\hline$p$-value & \multicolumn{2}{|c|}{0.97} & \multicolumn{2}{|c|}{0.77} & \multicolumn{2}{|c|}{0.97} & $0 .{ }^{\prime}$ & \\
\hline \multirow{2}{*}{$\begin{array}{l}\text { V-W Components } \\
\text { Models }\end{array}$} & \multicolumn{4}{|c|}{$C P Z-F F$} & \multicolumn{4}{|c|}{$C P Z-4 F$} \\
\hline & \multicolumn{2}{|c|}{ Single } & \multicolumn{2}{|c|}{ Rolling } & \multicolumn{2}{|c|}{ Single } & \multicolumn{2}{|c|}{ Rolling } \\
\hline cons & -0.18 & -0.31 & 0.18 & 0.50 & -0.25 & -0.41 & 0.11 & 0.30 \\
\hline$R m-R f$ & 0.71 & 1.17 & 0.26 & 0.72 & 0.80 & 1.30 & 0.36 & 0.98 \\
\hline$S M B_{-} C P Z$ & 0.13 & 0.77 & 0.02 & 0.15 & 0.11 & 0.67 & 0.02 & 0.15 \\
\hline$H M L_{-} C P Z$ & $0.6^{* * *}$ & 2.40 & $0.51^{* *}$ & 2.19 & $0.48^{* *}$ & 2.23 & $0.54^{* * *}$ & 2.50 \\
\hline$U M D \_C P Z$ & \multirow{2}{*}{\multicolumn{2}{|c|}{0.55}} & & & -0.94 & -1.23 & 0.24 & 0.61 \\
\hline Cross-sectional $\mathrm{R}^{2}$ & & & \multicolumn{2}{|c|}{0.54} & \multicolumn{2}{|c|}{0.56} & \multicolumn{2}{|c|}{0.55} \\
\hline$\chi^{2}$ & \multicolumn{2}{|c|}{19.30} & \multicolumn{2}{|c|}{20.00} & \multicolumn{2}{|c|}{13.50} & \multicolumn{2}{|c|}{21.60} \\
\hline$p$-value & \multicolumn{2}{|c|}{0.62} & 0 . & & & 38 & 0. & \\
\hline
\end{tabular}

\begin{tabular}{|c|c|c|c|c|c|c|c|c|}
\hline \multirow{3}{*}{$\begin{array}{l}\text { Panel B } \\
\text { Decomposed Models } \\
\text { cons }\end{array}$} & \multicolumn{4}{|c|}{ FF_4F_Decomp. } & \multicolumn{4}{|c|}{ CPZ_4F_Decomp. } \\
\hline & \multicolumn{2}{|c|}{ Single } & \multicolumn{2}{|c|}{ Rolling } & \multicolumn{2}{|c|}{ Single } & \multicolumn{2}{|c|}{ Rolling } \\
\hline & -0.25 & -0.45 & 0.00 & 0.02 & -0.22 & -0.38 & -0.23 & -0.62 \\
\hline$R m-R f$ & 0.79 & 1.37 & 0.52 & 1.42 & 0.77 & 1.25 & $0.76^{* *}$ & 2.13 \\
\hline$S M B$ & 0.07 & 0.40 & 0.07 & 0.37 & & & & \\
\hline$H M L \_S$ & 0.44 & 1.57 & 0.37 & 1.33 & & & & \\
\hline$H M L \_B$ & $0.48^{* *}$ & 2.12 & $0.46^{* *}$ & 2.18 & & & & \\
\hline$U M D$ & -0.46 & -0.70 & 0.02 & 0.08 & & & & \\
\hline$S M B_{-} C P Z$ & & & & & 0.11 & 0.67 & 0.03 & 0.16 \\
\hline$B H M L_{-} C P Z$ & & & & & $0.44^{*}$ & 1.83 & $0.46^{* *}$ & 2.07 \\
\hline$S H M L_{-} C P Z$ & & & & & $0.53^{* *}$ & 1.99 & 0.43 & 1.50 \\
\hline$U M D \_C P Z$ & & & \multirow{2}{*}{\multicolumn{2}{|c|}{0.56}} & -0.14 & -0.16 & 0.03 & 0.10 \\
\hline Cross-sectional $\mathrm{R}^{2}$ & \multicolumn{2}{|c|}{0.57} & & & & \multicolumn{2}{|c|}{0.56} \\
\hline$\chi^{2}$ & \multicolumn{2}{|c|}{11.81} & \multicolumn{2}{|c|}{19.15} & & & \multicolumn{2}{|c|}{15.96} \\
\hline$p$-value & \multicolumn{2}{|c|}{0.92} & \multicolumn{2}{|c|}{0.51} & \multicolumn{2}{|c|}{0.94} & \multicolumn{2}{|c|}{0.71} \\
\hline
\end{tabular}

Note:

The table reports the results of second stage Fama-MacBeth tests of the value-weighted returns of $25(5 \times 5)$ intersecting (independently sorted) size and book-to-market (BTM) portfolios on the six asset pricing models as specified in the text. Both the test portfolios and the risk factors used in the models are formed from the largest 350 firms. The two-pass Fama-MacBeth test, proceeds by estimating a vector of estimated factor loadings by regressing the time-series of excess returns on each test portfolio on the vector of risk factors which depends on the particular model being tested. The test then proceeds by running crosssectional regression for each month in the second pass as $R_{i}-R_{f}=\gamma_{0}+\gamma \hat{\beta}_{i}+\varepsilon_{i}$ where, $R_{i}$ is the return of test portfolio $i, R_{f}$ denotes the risk free return, $\gamma_{0}$ is the constant, $\gamma^{\prime}$ is the vector of cross-sectional regression coefficients and $\hat{\beta}$ is the vector of estimated factor loadings from the first pass regression. From the second pass cross-sectional regressions we obtain time series of $\gamma_{0 \mathrm{t}}$ and $\gamma_{t}$. The average premium $\gamma$ is calculated as 


\section{Table 13 (Continued)}

the mean of the time series $\gamma s$. $R m-R f$ is the market risk premium, SMB, HML and $U M D$ are formed from six intersecting portfolios formed yearly using market capitalisation and the book-to-market ratio and from intersecting portfolios formed monthly using size and 12 month past returns respectively as described in the text and on Ken French's website. $S M B_{-} C P Z, H M L_{-} C P Z$ and $U M D_{-} C P Z$ are formed using the market capitalisations of the intersecting size and book-to-market (BTM), and size and momentum portfolios as described in the text. $H M L_{-} S$ and $H M L_{-} B$ are decompositions of the HML factor as described in the text and in Fama and French (2011), whilst $M M B_{-} C P Z$ is the mid-cap minus large cap factor, $S M M_{-} C P Z$ is the small cap minus mid-cap factor, and $B H M L_{-} C P Z$ and $S H M L_{-} C P Z$ are the decompositions of the $H M L_{-} C P Z$ portfolio, as described in the text and Cremers et al. (2010). The Single column reports the result from first pass regressions run as single regression over the entire time-series while Rolling column reports the results from the 60 month rolling regressions. $\gamma$ is the average coefficient from the Fama-MacBeth second pass regressions, $t$-sh is the Shanken (1992) errors-in-variables corrected $t$-statistics, The Cross-sectional $\mathrm{R}^{2}$, the $\chi^{2}$ test for the pricing errors are jointly zero and the $p$-value corresponding to the $\chi^{2}$ are also reported. Panel A reports the results for the Basic models and the Value-weighted factor components models. Panel $\mathrm{B}$ reports the results of the Decomposed factor models. $* * *, * *$ and $*$ represent the significance at $1 \%, 5 \%$ and $10 \%$ significance levels, respectively.

In Table 11, we report the results of the Fama-MacBeth test on the 25 standard deviation portfolios. In Panel A, the chi-squared tests show that we cannot reject the null hypothesis that pricing errors are jointly zero for all the models. However for the Simple FF model, none of the factors are significantly priced, irrespective of whether a single regression or rolling regressions are employed. We also note that the constant is significant and positive. For the Simple $4 \mathrm{~F}$ model, conclusions vary according to whether a single regression or rolling regression is employed. For the former, nothing is priced, but for the latter, the constant is significant and $H M L$ is significantly priced at the $10 \%$ level.

Using CPZ weightings, the constant is always significant and positive. In the rolling regression version of the CPZ_FF model, the market factor is negatively priced. In both the single and rolling versions of the $\mathrm{CPZ}_{-} 4 \mathrm{~F}$ model, none of the factors are priced. Turning to the decomposed factor results in Table 11, Panel B, we can accept the null hypothesis of no significant pricing errors for all our models but unfortunately for the Fama-French (2011) decomposition, nothing is priced except for the constant term in the rolling regressions. With the $\mathrm{CPZ}$ decomposition run on a single regression basis, $U M D \_C P Z$ is priced, although at a level that is roughly twice its sample period mean. However, when we switch to rolling regressions, the sign on $U M D_{-} C P Z$ changes, although the coefficient is insignificant, and that BHML_CPZ now appears to be priced. However, the level of pricing implied is some five times its sample mean.

In conclusion on these second-stage pricing tests, if we follow the Lewellen et al. (2010) recommendations of looking at GRS and chi-squared tests, examining whether constant terms are significant, and checking whether the implied prices of factors seem plausible, we are forced to be sceptical on whether these models are informative on which risk factors are priced in the UK.

One interesting feature of the tests is that when the models are tested on the portfolios used to form the factors, the single regression tests yield slightly higher crosssectional R-squared than the rolling regressions. This is consistent either with a mean reversion effect in the factor loadings in these portfolios, or with the rolling regressions simply being noisier estimates of the true factor loadings. However, we do not observe such an effect when testing models on the volatility-ranked portfolios, when there is little to choose between the single and rolling regressions. Indeed, if anything the rolling regression approach provides weak evidence that HML (or a component of it 
Table 14

Fama-MacBeth Tests with the 12 Size, Book-to-Market and Momentum Portfolios Formed from the Largest 350 Firms

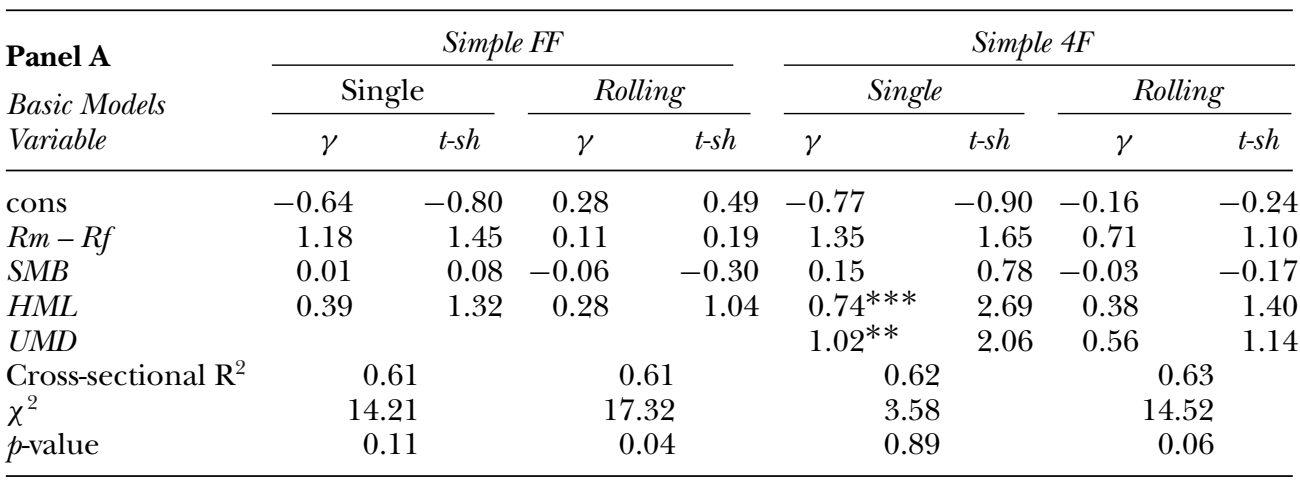

\begin{tabular}{|c|c|c|c|c|c|c|c|c|}
\hline \multirow{3}{*}{$\begin{array}{l}\text { V-W Components } \\
\text { Models } \\
\text { cons }\end{array}$} & \multicolumn{4}{|c|}{$C P Z-F F$} & \multicolumn{4}{|c|}{$C P Z-4 F$} \\
\hline & \multicolumn{2}{|c|}{ Single } & \multicolumn{2}{|c|}{ Running } & \multicolumn{2}{|c|}{ Single } & \multicolumn{2}{|c|}{ Running } \\
\hline & -0.35 & -0.40 & 0.63 & 1.08 & -0.18 & -0.21 & 0.24 & 0.37 \\
\hline$R m-R f$ & 0.87 & 0.98 & -0.26 & -0.47 & 0.71 & 0.81 & 0.28 & 0.48 \\
\hline$S M B_{-} C P Z$ & 0.06 & 0.33 & -0.05 & -0.26 & 0.14 & 0.76 & -0.03 & -0.14 \\
\hline$H M L_{-} C P Z$ & 0.43 & 1.61 & 0.24 & 0.89 & $0.69 * * *$ & 2.76 & 0.41 & 1.59 \\
\hline$U M D \_C P Z$ & \multirow{2}{*}{\multicolumn{2}{|c|}{0.60}} & & & 0.56 & 1.04 & $1.05^{*}$ & 1.71 \\
\hline Cross-sectional $\mathrm{R}^{2}$ & & & \multicolumn{2}{|c|}{0.61} & \multicolumn{2}{|l|}{0.62} & \multicolumn{2}{|c|}{0.63} \\
\hline$\chi^{2}$ & \multicolumn{2}{|c|}{14.21} & \multicolumn{2}{|c|}{17.40} & \multicolumn{2}{|l|}{11.32} & \multicolumn{2}{|c|}{12.03} \\
\hline$p$-value & \multicolumn{2}{|c|}{0.11} & \multicolumn{2}{|c|}{0.04} & \multicolumn{2}{|c|}{0.18} & \multicolumn{2}{|c|}{0.15} \\
\hline
\end{tabular}

\begin{tabular}{|c|c|c|c|c|c|c|c|c|}
\hline \multirow{3}{*}{$\begin{array}{l}\text { Panel B } \\
\text { Decomposed Models } \\
\text { cons }\end{array}$} & \multicolumn{4}{|c|}{ FF_4F_Decomp. } & \multicolumn{4}{|c|}{ CPZ_4F_Decomp. } \\
\hline & \multicolumn{2}{|c|}{ Single } & \multicolumn{2}{|c|}{ Rolling } & \multicolumn{2}{|c|}{ Single } & \multicolumn{2}{|c|}{ Rolling } \\
\hline & -1.02 & -1.13 & 0.79 & 0.66 & -1.62 & -1.58 & -0.04 & -0.06 \\
\hline$R m-R f$ & $1.6^{*}$ & 1.82 & -0.38 & -0.34 & $2.18^{* *}$ & 2.31 & 0.65 & 0.87 \\
\hline$S M B$ & 0.02 & 0.11 & -0.06 & -0.32 & & & & \\
\hline$H M L \_S$ & $0.64^{* *}$ & 2.19 & $0.69^{* *}$ & 2.29 & & & & \\
\hline$H M L \_B$ & $0.53^{* *}$ & 2.00 & 0.38 & 1.33 & & & & \\
\hline$U M D$ & $0.76^{*}$ & 1.67 & 0.62 & 1.21 & & & & \\
\hline$S M B_{-} C P Z$ & & & & & 0.21 & 1.10 & -0.02 & -0.12 \\
\hline$B H M L_{-} C P Z$ & & & & & 0.44 & 1.52 & 0.22 & 0.71 \\
\hline$S H M L_{-} C P Z$ & & & & & $0.68^{* *}$ & 2.23 & $0.83^{* * *}$ & 2.38 \\
\hline$U M D \_C P Z$ & & & & & $1.37 * *$ & 2.13 & $1.51^{* * *}$ & 2.49 \\
\hline Cross-sectional $\mathrm{R}^{2}$ & 0.6 & & 0.6 & & & & & \\
\hline$\chi^{2}$ & 3.2 & & 7.2 & & & & & \\
\hline$p$-value & 0.8 & & 0.4 & & & & & \\
\hline
\end{tabular}

Note:

The table reports the results of second stage Fama-MacBeth tests of the value-weighted returns of the $12(2 \times 2 \times 3)$ sequentially sorted size, book-to-market $(\mathrm{BTM})$ and momentum portfolios on the six asset pricing models as specified in the text. Both the test portfolios and the risk factors used in the models are formed from the largest 350 firms. The two-pass Fama-MacBeth test, proceeds by estimating a vector of estimated factor loadings by regressing the time-series of excess returns on each test portfolio on the vector of risk factors which depends on the particular model being tested. The test then proceeds by running cross-sectional regressions for each month in the second pass as $R_{i}-R_{f}=\gamma_{0}+\gamma \hat{\beta}_{i}+\varepsilon_{i}$ where, $R_{i}$ is the return of test portfolio $i, R_{f}$ denotes the risk free return, $\gamma_{0}$ is the constant, $\gamma^{\prime}$ is the vector of cross-sectional regression coefficients and $\hat{\beta}$ is the vector of estimated factor loadings from the first pass regression. From the second pass cross-sectional regressions we obtain time series of $\gamma_{0 \mathrm{t}}$ and $\gamma_{t}$. The average premium $\gamma$ is 


\section{Table 14 (Continued)}

calculated as the mean of the time series $\gamma s . R m-R f$ is the market risk premium, SMB, HML and $U M D$ are formed from six intersecting portfolios formed yearly using market capitalisation and the book-to-market ratio and from intersecting portfolios formed monthly using size and 12 month past returns respectively as described in the text and on Ken French's website. $S M B_{-} C P Z, H M L_{-} C P Z$ and $U M D_{-} C P Z$ are formed using the market capitalisations of the intersecting size and book-to-market (BTM), and size and momentum portfolios as described in the text. $H M L_{-} S$ and $H M L_{-} B$ are decompositions of the HML factor as described in the text and in Fama and French (2011), whilst $M M B_{-} C P Z$ is the mid-cap minus large cap factor, $S M M_{-} C P Z$ is the small cap minus mid-cap factor, and BHML_CPZ and SHML_CPZ are the decompositions of the $H M L_{-} C P Z$ portfolio, as described in the text and Cremers et al. (2010). The Single column reports the result from first pass regressions run as single regression over the entire time-series while Rolling column reports the results from the 60 month rolling regressions. $\gamma$ is the average coefficient from the Fama-MacBeth second pass regressions, $t$-sh is the Shanken (1992) errors-in-variables corrected $t$-statistics, The Cross-sectional $\mathrm{R}^{2}$, the $\chi^{2}$ test for the pricing errors are jointly zero and the $p$-value corresponding to the $\chi^{2}$ are also reported. Panel A reports the results for the Basic models and the Value-weighted factor components models. Panel B reports the results of the Decomposed factor models. $* * * * *$ and ${ }^{*}$ represent the significance at $1 \%, 5 \%$ and $10 \%$ significance levels, respectively.

in the case of the decomposed CPZ model) may be priced in the CPZ and decomposed models, whereas the single regression approach suggests otherwise. Given the weak explanatory power of these models, it is unwise to make too much of this, but it may be that factor loadings are more likely to be time varying when test portfolios are formed on characteristics that are not used in factor construction. Although we do not formally test this conjecture here, we note that this is entirely consistent with the evidence on industry factor loadings reported in Fama and French (1997) and Gregory and Michou (2009).

Given our scepticism on the adequacy of these asset pricing models, we run two further groups of tests. First, we undertake the robustness checks to ensure our results above are not driven by omitted variables or the period over which factor loadings are estimated. Second, observing that our models have particular difficulty in pricing smaller stocks, we examine whether we can find a model that works at least for larger and more liquid firms.

\section{ROBUSTNESS CHECKS}

\section{(i) APT Variants}

Our first robustness checks extend our models by including two variants of the Clare, Priestly and Thomas (1997) APT model. We do this because if such APT factors are priced in a manner not fully captured by size, BTM and momentum-based factors, then the above results might be explained by an omitted variables problem. First, we run the Clare et al. (1997) base model with all their variables excluding retail bank lending. ${ }^{16}$ Second, we include their variables as an extension to the FF and Carhart models. They do not appear to add anything to the basic FF and Carhart models, and none of these variables are priced in the Fama-MacBeth regressions, and so we do not report the results here.

16 We exclude bank lending for several reasons. First, the data are not currently available as a monthly series for our whole sample period. Second, Clare et al (1997) use the first difference of the natural logarithm of bank lending and as we find the series has negative values, using their definition on our observed data series is not possible here. We also note that this data series is extremely volatile on a monthly basis. 
Table 15

Fama-MacBeth Tests with the 12 Standard Deviation Portfolios Formed from the Largest 350 Firms

\begin{tabular}{|c|c|c|c|c|c|c|c|c|}
\hline \multirow{3}{*}{$\begin{array}{l}\text { Panel A } \\
\text { Basic Models } \\
\text { Variable }\end{array}$} & \multicolumn{4}{|c|}{ Simple FF } & \multicolumn{4}{|c|}{ Simple $4 F$} \\
\hline & \multicolumn{2}{|c|}{ Single } & \multicolumn{2}{|c|}{ Rolling } & \multicolumn{2}{|c|}{ Single } & \multicolumn{2}{|c|}{ Rolling } \\
\hline & $\gamma$ & $t$-sh & $\gamma$ & $t$-sh & $\gamma$ & $t$-sh & $\gamma$ & $t$-sh \\
\hline cons & 0.61 & 0.68 & $0.78^{*}$ & 1.68 & 0.72 & 0.68 & $0.89^{*}$ & 1.74 \\
\hline$R m-R f$ & 0.00 & 0.00 & -0.28 & -0.62 & 0.15 & 0.18 & -0.39 & -0.77 \\
\hline$S M B$ & -0.55 & -1.01 & -0.34 & -1.07 & -0.11 & -0.19 & -0.17 & -0.52 \\
\hline$H M L$ & -0.75 & -1.27 & 0.11 & 0.26 & -0.26 & -0.41 & 0.15 & 0.34 \\
\hline$U M D$ & \multirow{2}{*}{\multicolumn{2}{|c|}{0.50}} & & & $1.51^{* *}$ & 2.17 & -0.01 & -0.04 \\
\hline Cross-sectional $\mathrm{R}^{2}$ & & & \multicolumn{2}{|c|}{0.49} & \multicolumn{2}{|c|}{0.50} & \multicolumn{2}{|c|}{0.49} \\
\hline$\chi^{2}$ & \multicolumn{2}{|c|}{10.27} & \multicolumn{2}{|c|}{13.93} & \multicolumn{2}{|c|}{7.12} & \multicolumn{2}{|c|}{13.03} \\
\hline$p$-value & \multicolumn{2}{|c|}{0.59} & \multicolumn{2}{|c|}{0.30} & \multicolumn{2}{|c|}{0.78} & \multicolumn{2}{|c|}{0.29} \\
\hline \multirow{2}{*}{$\begin{array}{l}V \text {-W Components } \\
\text { model }\end{array}$} & \multicolumn{4}{|c|}{$C P Z-F F$} & \multicolumn{4}{|c|}{$C P Z-4 F$} \\
\hline & \multicolumn{2}{|c|}{ Single } & \multicolumn{2}{|c|}{ Running } & \multicolumn{2}{|c|}{ Single } & \multicolumn{2}{|c|}{ Running } \\
\hline cons & 0.76 & 0.83 & 0.79 & 1.61 & 1.05 & 0.08 & 0.81 & 1.57 \\
\hline$R m-R f$ & -0.17 & -0.18 & -0.32 & -0.70 & -0.52 & -0.54 & -0.34 & -0.66 \\
\hline$S M B_{-} C P Z$ & -0.12 & -0.27 & 0.00 & 0.03 & 0.01 & 0.04 & 0.02 & 0.10 \\
\hline$H M L_{-} C P Z$ & 0.22 & 0.34 & 0.40 & 1.08 & 0.80 & 1.17 & 0.36 & 0.95 \\
\hline$U M D_{-} C P Z$ & & & & & $1.82^{* * *}$ & 2.45 & 0.01 & 0.03 \\
\hline Cross-sectional $\mathrm{R}^{2}$ & \multicolumn{2}{|c|}{0.49} & & 47 & & & & \\
\hline$\chi^{2}$ & 11. & & & & & & & \\
\hline$p$-value & & & & 32 & & & & \\
\hline Panel B & & $F F_{-} 4 F_{-} I$ & ecomp. & & & $C P Z_{-} 4 F$ & Decomp. & \\
\hline Decomposed Models & $\operatorname{Sin}$ & & & $i n g$ & & & & \\
\hline cons & 0.92 & 0.90 & 0.58 & 1.09 & 1.21 & 0.87 & 0.52 & 0.99 \\
\hline$R m-R f$ & -0.36 & -0.40 & -0.03 & -0.07 & -0.68 & -0.66 & -0.01 & -0.02 \\
\hline$S M B$ & -0.23 & -0.38 & -0.17 & -0.51 & & & & \\
\hline$H M L_{-} S$ & -0.26 & -0.43 & 0.50 & 1.03 & & & & \\
\hline$H M L \_B$ & 0.78 & 1.16 & -0.11 & -0.27 & & & & \\
\hline$U M D$ & $1.31^{* *}$ & 1.92 & -0.01 & -0.04 & & & & \\
\hline$S M B_{-} C P Z$ & & & & & -0.02 & -0.06 & 0.02 & 0.09 \\
\hline$B H M L_{-} C P Z$ & & & & & 0.98 & 1.35 & -0.07 & -0.16 \\
\hline$S H M L_{-} C P Z$ & & & & & -0.19 & -0.33 & 0.48 & 0.99 \\
\hline$U M D_{-} C P Z$ & & & & & $1.61^{* *}$ & 2.06 & 0.20 & 0.40 \\
\hline Cross-sectional $\mathrm{R}^{2}$ & & & & 50 & & & & \\
\hline$\chi^{2}$ & & & & & & & & \\
\hline$p$-value & & & & 15 & & & & \\
\hline
\end{tabular}

Note:

The table reports the results of second stage Fama-MacBeth tests of the value-weighted returns of the $1212(2 \times 2 \times 3)$ sequentially sorted size, book-to-market $(\mathrm{BTM})$ and momentum portfolios on the six asset pricing models as specified in the text. Both the test portfolios and the risk factors used in the models are formed from the largest 350 firms. The two-pass Fama-MacBeth test, proceeds by estimating a vector of estimated factor loadings by regressing the time-series of excess returns on each test portfolio on the vector of risk factors which depends on the particular model being tested. The test then proceeds by running cross-sectional regression for each month in the second pass as $R_{i}-R_{f}=\gamma_{0}+\gamma \hat{\beta}_{i}+\varepsilon_{i}$ where, $R_{i}$ is the return of test portfolio $i, R_{f}$ denotes the risk free return, $\gamma_{0}$ is the constant, $\gamma^{\prime}$ is the vector of cross-sectional regression coefficients and $\hat{\beta}$ is the vector of estimated factor loadings from the first pass regression. From the second pass cross-sectional regressions we obtain time series of $\gamma_{0 \mathrm{t}}$ and $\gamma_{t}$. The average premium $\gamma$ is 


\section{Table 15 (Continued)}

calculated as the mean of the time series $\gamma s . R m-R f$ is the market risk premium, $S M B, H M L$ and $U M D$ are formed from six intersecting portfolios formed yearly using market capitalisation and the book-to-market ratio and from intersecting portfolios formed monthly using size and 12 month past returns respectively as described in the text and on Ken French's website. $S M B_{-} C P Z, H M L_{-} C P Z$ and $U M D_{-} C P Z$ are formed using the market capitalisations of the intersecting size and book-to-market (BTM), and size and momentum portfolios as described in the text. $H M L_{-} S$ and $H M L_{-} B$ are decompositions of the HML factor as described in the text and in Fama and French (2011), whilst $M M B_{-} C P Z$ is the mid-cap minus large cap factor, $S M M_{-} C P Z$ is the small cap minus mid-cap factor, and BHML_CPZ and SHML_CPZ are the decompositions of the $H M L_{-} C P Z$ portfolio, as described in the text and Cremers et al. (2010). The Single column reports the result from first pass regressions run as single regression over the entire time-series while Rolling column reports the results from the 60 month rolling regressions. $\gamma$ is the average coefficient from the Fama-MacBeth second pass regressions, $t$-sh is the Shanken (1992) errors-in-variables corrected $t$-statistics, The Cross-sectional $\mathrm{R}^{2}$, the $\chi^{2}$ test for the pricing errors are jointly zero and the $p$-value corresponding to the $\chi^{2}$ are also reported. Panel A reports the results for the Basic models and the Value-weighted factor components models. Panel B reports the results of the Decomposed factor models. $* * * * *$ and ${ }^{*}$ represent the significance at $1 \%, 5 \%$ and $10 \%$ significance levels, respectively.

\section{(ii) Alternative Time Horizons}

Kothari, Shanken and Sloan (1995) show that conclusions drawn on tests of the CAPM are sensitive to the period over which betas are estimated. To test whether such an effect is important in the UK, we follow Fletcher (2010) and run tests using quarterly data. The principal effect on our results is that the spread of observed betas appears to increase in tests using the 25 standard deviation portfolios. However, our observations on the pricing of risk factors in the second stage regression tests do not change. Whilst results from the robustness checks above are not reported for space reasons, they are available from the authors on request.

\section{(iii) Tests on Large Firms}

Fama and French (2011) note that smaller stocks are particularly challenging to price. As we observe above, whilst there may be good reasons why arbitrage activity is restricted in smaller stocks, those reasons do not apply to the universe of larger and more liquid stocks. As a proxy for this tradable universe, we next limit our factor formation and test portfolios to the largest 350 firms (excluding financials) by market capitalisation. ${ }^{17,18}$ Factor means are close to zero for $S M B, 0.32 \%$ per month for $H M L$, and $0.63 \%$ per month for UMD. Our test portfolios are $25(5 \times 5)$ size and BTM sorts of the top 350 firms, $12(2 \times 2 \times 3)$ size, BTM and momentum portfolios sorted sequentially and 12 portfolios sorted on prior volatility.

We do not report the detailed intercept coefficients and $t$-statistics for each set of portfolios as we do for the full sample, but instead report just the GRS F-test statistic, the associated $p$-value, and the average adjusted R-squared across all the test portfolios. These results are striking and are reported in Table 12. Using each of our six models, and our three portfolio formation methods, we only reject the null hypothesis of alphas being jointly zero in one case, which is for the CPZ_FF model tested on the standard deviation portfolios. The FF models do well when tested on the size and BTM portfolios, and the $4 \mathrm{~F}$ models do better when tested on the size, BTM and momentum portfolios, which is perhaps not surprising given that as Fama and French (2011) 
observe, these models are playing "home games". Note also that the decomposed factor models seem to do a little better than the aggregated models.

Tables 13-15 report the full Fama-MacBeth tests. Turning to the tests based on size and BTM sorted portfolios first, we see that the Table 13, Panel A results suggest that the basic FF model has an insignificant chi-squared test for both single and rolling regressions, with a constant term not significantly different from zero. The $H M L$ factor seems to be priced at plausible levels in both specifications, and although $R m-R f$ has a positive coefficient, no other factors are significantly priced. Moving to the basic Carhart model does not change these basic conclusions, and neither does the adoption of the CPZ weightings of the factor components make much difference.

In Table 13, Panel B, for the decomposed models, we cannot reject the null hypothesis of no jointly significant pricing errors for either model no matter how the coefficient estimates are formed. In the $\mathrm{FF} \_4 \mathrm{~F}$ model, only $H M L_{-} B$ is priced, suggesting that the value premium is more important in the largest subset of firms. However, when the CPZ_4F model is estimated on a single regression basis, both BHML_CPZ and $S H M L_{-} C P Z$ appear to be priced. These conclusions change when the model is estimated on a rolling basis, when the market risk premium, $R m-R f$, and BHML_CPZ are priced. Taken as a whole, these results suggest that $H M L$ is consistently priced, that the large firm element of this value premium is consistently priced, but that conclusions on the pricing of other factors are sensitive both to the model employed and on whether or not rolling estimates are made.

We next examine the performance of these models when tested against size, BTM and momentum portfolios. Table 14, Panel A reveals that both the basic and CPZ versions of the FF models fail the chi-squared test when estimated using rolling regressions. Furthermore, none of the factors in either version of the model are priced. When we switch to the basic Carhart model, estimated on a single regression basis, both $H M L$ and $U M D$ appear to be priced, the intercept term is zero, and we cannot reject the null hypothesis of no significant pricing errors. However, the implied prices of the factors are some way in excess of the sample means. We also note that the market factor is just significant at the $10 \%$ level, although the factor price implied again seems high. When we estimate the model on a rolling basis, we can reject the null hypothesis and no factors are priced. For the CPZ_4F model, whilst we are not able to reject the null hypothesis for either single or rolling regression estimates and the intercept is not significantly different from zero in either case, the conclusion on which factor is priced differs according to how the regression is estimated. For the single regression basis, $H M L_{-} C P Z$ is priced, whilst for the rolling regression basis it is $U M D_{-} C P Z$ that is priced.

The decomposed factor models in Table 14 Panel B all pass the chi-squared test for the joint significance of pricing errors, and in all cases the intercept term is insignificant. When we estimate the $\mathrm{FF}_{4} 4 \mathrm{~F}$ model on a single regression basis, it appears that $R m-R f, H M L_{-} S, H M L_{-} B$ and $U M D$ factors are all priced. Whilst the $H M L$ components and momentum are priced at plausible levels, the implied price of the market factor, at $1.6 \%$ per month, seems to be three times higher than might reasonably be expected. When we switch to estimating the model on a rolling basis, only $H M L_{-} S$ is priced. The alternative $\mathrm{CPZ}_{-} 4 \mathrm{~F}$, estimated on a single regression basis, again shows that $R m-R f$ and momentum are priced, along with SHML. Once again, though, the implied price of the market risk factor is implausible. When estimated on a rolling regression basis, only $S H M L_{-} C P Z$ and $U M D_{-} C P Z$ are priced. 
When we employ test portfolios formed on the basis of prior 12-month standard deviation, from the tests in Panel A, it is clear that we can reject the FF model no matter how the factors are formed. Despite the chi-squared tests being insignificant, factors are never priced at levels even close to being significant. A similar conclusion is reached when estimating the basic Carhart model on a rolling basis. When the models are estimated using a single regression, $U M D$ and $U M D_{-} C P Z$ are both priced, but at implausibly high levels. Finally, we turn to the decomposed models in Table 15, Panel B. Briefly summarised, disaggregation adds little to the Carhart models described earlier. In both cases, momentum is priced only when single regression estimates are made. Whilst the implied prices are still high, they are somewhat dampened down compared to the estimates from Panel A.

Unfortunately, then, it appears that even restricting the pricing model to large firms fails to lead to a wholly convincing model when subject to the more stringent tests suggested by Lewellen et al. (2010). Whilst the GRS tests are satisfied for large firms, the second stage Fama-MacBeth tests are not supportive of factors being consistently priced in a UK context. However, if we restrict the tests to "home game" portfolios then we find some evidence that both the market risk premium and HML may be priced in large firms.

\section{CONCLUSION}

It seems clear from the evidence in Fama and French (2011) that within Europe, either the three factor or four factor model has problems when it comes to pricing portfolios with a momentum tilt, even when factors are formed on a local basis. Our particular interest in this paper is in the largest of the European markets, the UK. In the spirit of the Fama and French (2011) investigation, our first contribution in this paper has been to test alternative versions of the FF and Carhart models, using different approaches to factor construction, including the market capitalisation weightings of the constituent components of $S M B$ and HML along the lines suggested by Cremers et al. (2010). We also extend these basic models by including the factor decompositions suggested by Fama and French (2011) and Cremers et al. (2010). Our second contribution is to subject these models to various robustness checks, including the addition of the Clare et al. (1997) APT factors, the examination of quarterly estimation of factor loadings, and testing the model using factors and test portfolios formed from larger and more liquid firms.

Throughout, we are mindful of the "sceptical" approach to asset pricing advocated by Lewellen et al. (2010) and subject our asset pricing models to the following requirements: i) that they have to price portfolios formed on the basis of a variable not used to form the factors themselves (and here we follow their suggestion of using test portfolios formed on the basis of prior volatility); ii) requiring that in addition to satisfying the null hypothesis of no jointly significant pricing errors, intercepts should be zero, and iii) that the implied factor prices should be plausible. Whilst we can find models that price BTM portfolios, at least when we restrict the analysis to larger firms, as Fama and French (2011) note, such models are playing "home games". Unfortunately, when confronted with "away games", such models prove not to be robust.

The results of our asset pricing tests confirm and extend the findings of MMS by applying tests to a wider set of portfolios and also by adding tests based on the 
4-factor Carhart model. Our first stage tests are consistent with those from the European results of Fama and French (2011). However, we show that value weighting and decomposing factors leads to a modest improvement in performance, and that when factors are formed excluding smaller firms, and tests carried out on test portfolios excluding small firms, any of the versions of the factor models we investigate provides a plausible explanation of the cross-section of UK returns. In particular, the value-weighted decomposed model CPZ_4F seems to offer a marginal advantage over the other five. This can be interpreted as good news for those interested in long run event studies or portfolio performance evaluation in larger firms, though clearly those interested in researching smaller companies and momentum effects in such firms will take little comfort from this. The solution may lie in the use of control portfolios in such studies. Whilst in this paper we do not undertake an analysis of the properties of long run abnormal returns using control portfolios, as in Lyon et al. (1999), we view this as an interesting task worthy of a detailed paper in its own right. We leave this for future research, but we hope that it is one we can help facilitate through this paper, together with the factors and portfolios available on our website.

When it comes to the second-stage Fama-MacBeth tests, we share Fletcher's (2010) views on the inability of unconditional factor models to predict the cost of equity for UK firms. There is evidence that $H M L$ is priced, and some that $U M D$ is priced. In this regard, we note that Mouselli, Michou and Stark (2008) provide some evidence for an economic interpretation of the $H M L$ factor. In a US context, Aretz, Bartram and Pope (2010) show that book-to-market effects convey information about the term structure of interest rates, and that $U M D$ is significantly associated with default risk, term structure and foreign exchange risk. However, these factors are not reliably priced when we switch test portfolios, and that must be the cause for some concern.

What we do not attempt here is to test whether conditional versions of the factor models might explain the cross-section of expected returns. One attempt, in Gregory and Michou (2009), shows that conditional versions of the CAPM and three-factor models as employed by Ferson and Harvey (1999) and Fama and French (1997) are unlikely to be the solution. More recently, Fletcher (2010) finds that a conditional version of the FF model is the best performing model in his range of tests, although it performs poorly in out of sample tests. However, conditional versions using the frameworks of any of Jaganathan and Wang (1996), Lewellen and Nagel (2006) ${ }^{19}$ or Koch and Westheide (2009) may offer a way forward.

A further possibility is that the estimation window for factor loadings matters. In the spirit of Kothari et al. (1995), we have examined whether quarterly estimation windows make a difference, finding that they do not. A longer run series of data, such as that used in Fletcher (2010), might allow testing using annual estimation of factor loadings, as in Kothari et al. (1995). Such an approach would be interesting if factor loadings were time varying but mean-reverting. Alternatively, we could explore the other extreme. If factor loadings are time-varying, but with no tendency to mean revert, then using long run estimation windows may bias our tests against our factor models, even if they hold. We note that UK regulators tend to favour the estimation of betas using daily or weekly returns, rather than monthly returns. So an interesting question for future research is whether very long windows using annual data, or

19 Note that although Lewellen and Nagel (2006) reject the idea of the conditional CAPM explaining returns, a more recent paper by O'Doherty (2009) claims that it can explain the financial distress anomaly. 
alternatively much shorter windows using daily or weekly data, would result in more reliable models.

Of course, it may be that there are simply better factors that might explain the crosssection of returns. Chen et al. (2011) propose supplementing the market factor with factors reflecting investment and return on equity. Clubb and Naafi (2007) provide additional motivation for a model that incorporates information about forecast ROE. Other candidates for potential factors might include variables related to financial distress and factors related to earnings quality (Kim and Qi, 2010). Alternatively, a more sophisticated macroeconomic fundamentals model of the type investigated in Aretz et al. (2010) might provide a way forward. A further potential line of enquiry is to examine whether asset pricing tests are better tested using implied, rather than realised, cost of capital. One argument, found in Lee et al. (2009), is that models of expected return fail asset pricing tests because realised returns are "extremely noisy" proxies for expected returns. Using an alternative model of implied cost of capital, Hou et al. (2010) show that some anomalies found in realised returns disappear in tests using implied returns.

In conclusion, whilst the search for a more convincing UK asset pricing model remains, in that we have not been able to demonstrate that the factors investigated in this paper are consistently and reliably priced in second stage Fama-MacBeth tests, we have some positive recommendations for researchers interested in long-run event studies and portfolio performance evaluation. Given this, we provide all of the factors used in this paper on our website to facilitate such research.

\section{REFERENCES}

Agarwal, V., R. Taffler and M. Brown (2011), 'Is Management Quality Value Relevant?' Journal of Business Finance $\mathcal{E}$ Accounting, Vol. 38, Nos. 9\&10, pp. 1, 184-208.

Ali, A. and M.A. Trombley (2006), 'Short Sales Constraints and Momentum in Stock Returns', Journal of Business Finance E Accounting, Vol. 33, Nos. 3\&4, pp. 587-615.

Ali, A., L-S. Huang and M.A. Trombley (2003), 'Arbitrage Risk and the Book-to-Market Mispricing', Journal of Financial Economics, Vol. 69, No. 2, pp. 355-73.

Agarwal, V. and R. Taffler (2008), 'Does Financial Distress Risk Drive the Momentum Anomaly?' Financial Management, Vol. 37, No. 3, pp. 461-84.

Al-Horani, A., P.F. Pope and A.W. Stark (2003), 'Research and Development Activity and Expected Returns in the United Kingdom', European Finance Review, Vol. 7, No. 1, pp. 27-46.

Antoniou, C., J. Doukas and A. Subrahmanyam (2012), 'Sentiment and Momentum', Journal of Financial and Quantitative Analysis, forthcoming.

Aretz, K., S.F. Bartram and P.F. Pope (2010), 'Macroeconomic Risks and Characteristic-based Factor Models', Journal of Banking Eं Finance, Vol. 34, pp. 1383-99.

Brooks, C., L. Xiafei and J. Miffre (2011), 'Idiosyncratic Risk and the Pricing of PoorlyDiversified Portfolios'. Available at SSRN: http://ssrn.com/abstract=1855944

Bulkley, G. and V. Nawosah (2009), 'Can the Cross-Sectional Variation in Expected Stock Returns Explain Momentum?' Journal of Financial and Quantitative Analysis, Vol 44, No. 4, pp. 777-94.

Campbell, J.Y. and T. Vuolteenaho (2004), 'Bad Beta, Good Beta', American Economic Review, Vol. 94, No. 5, pp. 1,249-75.

Carhart, M. (1997), 'On Persistence in Mutual Fund Performance', Journal of Finance, Vol. 52, No. 1, pp. 57-82.

Chen, L., N-M. Robert and L. Zhang (2011), 'An Alternative Three-Factor Model' Available at SSRN: http://ssrn.com/abstract $=1418117$

Christidis, A. C-Y and A. Gregory (2010), 'Some New Models for Financial Distress Prediction in the UK', Xfi - Centre for Finance and Investment Discussion Paper No. 
10 (University of Exeter: Xfi Centre for Finance and Investment). Available at SSRN: http://ssrn.com/abstract=1687166.

Clare, A.D., R. Priestly and S.H. Thomas (1997), 'The Robustness of the APT to Alternative Estimators', Journal of Business Finance and Accounting, Vol. 24, No. 5, pp. 645-55.

Clubb, C. and M. Naffi (2007), 'The Usefulness of Book-to-Market and ROE Expectations for Explaining UK Stock Returns', Journal of Business Finance $\mathcal{E}$ Accounting, Vol. 34, Nos. 1\&2, pp. 1-32.

Cochrane, J. H. (2001), Asset Pricing (Princeton, NJ: Princeton University Press).

Cremers, M., A. Petajisto and E. Zitzewit (2010), 'Should Benchmark Indices Have Alpha? Revisiting Performance Evaluation', EFA 2009 Bergen Meetings Paper; AFA 2010 Atlanta Meetings Paper. Available at SSRN: http://ssrn.com/abstract=1108856

Dedman, E., S. Mouselli, Y. Shen and A.W. Stark (2009), 'Accounting, Intangible Assets, Stock Market Activity and Measurement and Disclosure Policy - Views From the UK', Abacus, Vol. 45 , pp. 312-41.

Dimson, E., S. Nagel and G. Quigley (2003), 'Capturing the Value Premium in the United Kingdom', Financial Analysts Journal, Vol. 59, No. 6, pp. 35-45.

Dissanaike, G. and K.-H. Lim (2010), 'The Sophisticated and the Simple: the Profitability of Contrarian Strategies', European Financial Management, 16, pp. 229-55.

Fama, E.F. (1991), 'Efficient Capital Markets: II', Journal of Finance, Vol. 46, No. 5, pp. 1,575-617. Fama, E.F. and K.R. French (1992), 'The Cross Section of Expected Returns', Journal of Finance, Vol. 47, No. 2, pp. 427-65.

Fama, E.F. and K.R. French (1993), 'Common Risk Factors in the Returns on Stocks and Bonds', Journal of Financial Economics, Vol. 33, No. 1, pp. 3-56.

Fama, E.F. and K.R. French (1995), 'Size and Book-to-Market Factors in Earnings and Returns', Journal of Finance, Vol. 50, No. 1, pp. 131-56.

Fama, E.F. and K.R. French (1996), 'Multifactor Explanations of Asset Pricing Anomalies', Journal of Finance, Vol. 51, No. 1, pp. 55-84.

Fama, E.F. and K.R. French (1997), 'Industry Costs of Equity', Journal of Financial Economics, Vol. 43, pp. 153-93.

Fama, E.F. and K.R. French (2011), 'Size, Value and Momentum in International Stock Returns', Fama-Miller Working Paper; Tuck School of Business Working Paper No. 2011-85; Chicago Booth Research Paper No. 11-10. Available at SSRN: http://ssrn.com/abstract=1720139.

Fama, E.F. and J.D. MacBeth (1973), 'Risk, Return and Equilibrium: Empirical Tests', The Journal of Political Economy, Vol. 81, No. 3, pp. 607-36.

Ferson, W.E. and C.R. Harvey (1999), 'Conditioning Variables and the Cross-Section of Stock Returns', Journal of Finance, Vol. 54, No. 4, pp. 1,325-60.

Fletcher, J. (2001), 'An Examination of Predictable Risk and Return in UK Stock Returns', Journal of Economics and Business, Vol. 53, No. 6, pp. 527-46.

Fletcher, J. (2010), 'Arbitrage and the Evaluation of Linear Factor Models in UK Stock Returns', The Financial Review, Vol. 45, No. 2, pp. 449-68.

Fletcher, J. and D. Forbes (2002), 'An Exploration of the Persistence of UK Unit Trust Performance', Journal of Empirical Finance, Vol. 9, No. 5, pp. 475-93.

Fletcher, J. and J. Kihanda (2005), 'An Examination of Alternative CAPM-based Models in UK Stock Returns', Journal of Banking E Finance, Vol. 29, No. 12, pp. 2,995-3,014

Gibbons, M., S.A. Ross and J. Shanken (1989), 'A Test of the Efficiency of a Given Portfolio', Econometrica, Vol. 57, No. 5, pp. 1,121-52.

Gregory, A., C. Guermat and F. Al-Shawawreh (2010), 'UK IPOs: Long Run Returns, Behavioural Timing and Pseudo Timing', Journal of Business Finance and Accounting, Vol. 37, Nos. 5\&6, pp. 612-47.

Gregory, A., R.D.F. Harris and M. Michou (2001), 'An Analysis of Contrarian Investment Strategies in the UK', Journal of Business Finance and Accounting, Vol. 28, Nos. 9\&10, pp. 1193-1228.

Gregory, A., R.D.F. Harris and M. Michou (2003), 'Contrarian Investment and Macroeconomic Risk', Journal of Business Finance and Accounting, Vol. 30, Nos. 1\&2, pp. 213-55.

Gregory, A. and M. Michou (2009), 'Industry Cost of Equity Capital: UK Evidence', Journal of Business Finance Eै Accounting, Vol. 36, Nos. 5\&6, pp. 679-704. 
Gregory, A., R. Tharyan and I. Tonks (2011), 'More than Just Contrarians: Insider Trading in Glamour and Value Firms', European Financial Management, forthcoming.

Gregory, A. and J. Whittaker (2007), 'Performance and Performance Persistence of 'Ethical' Unit Trusts in the UK,' Journal of Business Finance $\mathcal{E} 0$ Accounting, Vol. 34, Nos. $7 \&$ 8, pp. $1,327-44$.

Griffin, J.M. (2002), 'Are the Fama and French Factors Global or Country Specific?' Review of Financial Studies, Vol. 15, No. 3, pp. 783-803.

Hou, K., M.A. van Dijk and Y. Zhang (2010), ' The Implied Cost of Capital: A New Approach', Fisher College of Business Working Paper No. 2010-03-004. Available at SSRN: http://ssrn.com/abstract=1561682.

Hussain, S. I., J. S. Toms and S. Diacon (2002), 'Financial Distress, Market Anomalies and Single and Multifactor Asset Pricing Models: New Evidence'. Available at SSRN: http://ssrn.com/abstract $=313001$

Jaganathan, R. and Z. Wang (1996), 'The Conditional CAPM and the Cross-Section of Expected Returns', Journal of Finance, Vol. 51, No. 1, pp. 3-54.

Jegadeesh, N. and S. Titman (1993), 'Returns to Buying Winners and Selling Losers: Implications for Stock Market Efficiency', Journal of Finance, Vol. 48, No. 1, pp. 65-91.

Jegadeesh, N. and S. Titman (2001), 'Profitability of Momentum Strategies: An Evaluation of Alternative Explanations', Journal of Finance, Vol. 56, No. 2, pp. 699-720.

Kim, D. and Y. Qi (2010), 'Accruals Quality, Stock Returns and Macroeconomic Conditions', The Accounting Review, Vol. 85, No. 3, pp. 937-78.

Koch, S. and C. Westheide (2009), 'The Conditional Relation between Fama-French Betas and Return'. Available at SSRN: http://ssrn.com/abstract=1283170.

Kothari, S.P., J. Shanken and R.G. Sloan (1995), 'Another Look at The Cross-Section of Expected Stock Returns', Journal of Finance, Vol. 50, No. 1, pp. 185-224.

Lee, C. M. C., Ng. David and B. Swaminathan (2009), 'Testing International Asset Pricing Models using Implied Costs of Capital', Journal of Financial and Quantitative Analysis, Vol. 44, No. 2, pp. 307-35.

Lewellen, J. and S. Nagel (2006), 'The Conditional CAPM Does Not Explain Asset-Pricing Anomalies', Journal of Financial Economics, Vol. 82, No. 2, pp. 289-314.

Lewellen, J., S. Nagel and J. Shanken (2010), 'A Skeptical Appraisal of Asset-Pricing Tests', Journal of Financial Economics, Vol. 96, pp. 175-94.

Liu, W., N. Strong and X.Z. Xu (1999), 'The Profitability of Momentum Investing', Journal of Business Finance EO Accounting, Vol. 26, Nos. 9\&10, pp. 1043-91.

Lo, A. W. and A.C. MacKinlay (1990), 'Data-Snooping Biases in Tests of Financial Asset Pricing Models', The Review of Financial Studies, Vol. 3, No. 3, pp. 431-67.

Loughran, T. and J. R. Ritter (1995), 'The New Issues Puzzle', Journal of Finance, Vol. 50, No. 1, pp. 23-51.

Loughran, T. and J. R. Ritter (2000), 'Uniformly Least Powerful Tests of Market Efficiency', Journal of Financial Economics, Vol. 55, No. 3, pp. 361-89.

Lyon, J.D., B.M. Barber and C. Tsai (1999), 'Improved Methods for Tests of Long-Run Abnormal Stock Returns', The Journal of Finance, Vol. 54, No. 1, pp. 165-201.

Michou, M., S. Mouselli and A.W. Stark (2012), 'Estimating the Fama and French Factors in the UK: An Empirical Review', Manchester Business School Working paper No. 505 (Manchester University: Manchester Business School).

Michou, M., S. Mouselli and A.W. Stark (2008), 'On the Information Content of the Fama and French Factors in the UK', Manchester Business School working paper No. 559, Available at: http://www.mbs.ac.uk/cgi/apps/research/working-papers/view/?wId=166

Miles, D. and A. Timmermann (1996), 'Variation in Expected Stock Returns: Evidence on the Pricing of Equities from a Cross-section of UK Companies', Economica, Vol. 63, No. 251, pp. 369-82.

Nagel, S. (2001), 'Accounting Information Free of Selection Bias: A New UK Database 1953-1999', London Business School Working Paper. Available at SSRN: http:/ /ssrn.com/abstract=286272 or doi:10.2139/ssrn.286272

O'Doherty, M.S. (2010), Information Risk, Conditional Betas, and the Financial Distress Anomaly. Available at SSRN: http://ssrn.com/abstract=1309827 
Shanken, J. (1992), 'On the Estimation of Beta-Pricing Models', The Review of Financial Studies, Vol. 5, No. 1, pp. 1-33.

Thomas, S. (2006), 'Discussion of Short Sales Constraints and Momentum in Stock Returns', Journal of Business Finance E Accounting, Vol. 33, Nos. 3\&4, pp. 624-25.

Zhang, L. (2005), 'The Value Premium', Journal of Finance, Vol. 60, No. 1, pp. 67-103.

Zhang, C. (2008), 'Decomposed Fama-French Factors for the Size and Book-to-Market Effects', Hong Kong University of Science and Technology Paper. Available at http://69.175.2.130/finman/Xiamen/szbm1.pdf (accessed 10 September 2010). 